\title{
2-(Pyridin-4yl)benzothiazole and Its Benzimidazole-Analogue: Biophysical and in silico Studies on Their Interaction with Urease and in vitro Anti-Helicobacter pylori Activities
}

\author{
Camila P. Pereira, ${ }^{a, b}$ Ana C. F. de Lyra, ${ }^{c}$ Breno G. F. Oliveira, ${ }^{a}$ Igor J. S. Nascimento, ${ }^{c}$ \\ Edeildo F. da Silva-Júnior, ${ }^{c}$ Thiago M. de Aquino, ${ }^{c}$ Francesca Sisto, ${ }^{d}$ Isis M. Figueiredo, ${ }^{c}$ \\ Felipe T. Martins, ${ }^{e}$ Luzia V. Modolo, ${ }^{\circledR b}$ Josué C. C. Santos ${ }^{\circledR} *, c$ and Ângelo de Fátima ${ }^{\circledR} *, a$ \\ ${ }^{a}$ Departamento de Química, Universidade Federal de Minas Gerais, \\ 31270-901 Belo Horizonte-MG, Brazil \\ ${ }^{b}$ Departamento de Botânica, Universidade Federal de Minas Gerais, \\ 31270-901 Belo Horizonte-MG, Brazil \\ 'Instituto de Química e Biotecnologia, Universidade Federal de Alagoas, \\ 57072-900 Maceió-AL, Brazil \\ ${ }^{d}$ Department of Biomedical, Surgery and Dental Sciences, Università degli Studi di Milano, \\ 20122 Milano, Italy \\ eInstituto de Química, Universidade Federal de Goiás, 74690-900 Goiânia-GO, Brazil
}

\begin{abstract}
In this study, the interaction between benzothiazole (BTA, concentration of a drug required for $50 \%$ inhibition in vitro $\left(\mathrm{IC}_{50}\right)=0.77 \mathrm{mM}$ ) and benzimidazole $\left(\mathrm{BIA}, \mathrm{IC}_{50}=2.14 \mathrm{mM}\right.$ ) with urease was quantitatively assessed, using UV-Vis, molecular fluorescence, and circular dichroism. The results showed that both compounds interact with urease by a static fluorescence quenching mechanism with a non-fluorescent complex formation. The main forces responsible for stabilizing the supramolecular complex between BTA and urease were hydrophobic while, for BIA, van der Waals interactions and hydrogen bonds were the main ones. Urease conformation changes due to the interaction process were analyzed by circular dichroism and synchronous fluorescence. Besides, a competitive assay with substrate and inhibitors was used to evaluate the preferential urease site of interaction with BTA and BIA. Our experimental and theoretical studies supported that both, BTA and BIA, are mixed-inhibitors of ureases with a slight preference to the active site of such enzymes. Finally, both BTA and BIA showed to possess anti-Helicobacter pylori (one reference strain and six clinical isolates) activity, presenting minimal inhibitory concentration (MIC) values ranging from 38-150 and 20-164 $\mu \mathrm{M}$, respectively. The urease inhibitors omeprazole and hydroxyurea showed MIC values in the range of 46-185 $\mu \mathrm{M}$ and 1683-> $3366 \mu \mathrm{M}$, respectively.
\end{abstract}

Keywords: urease, urease inhibitor, benzothiazole, benzimidazole, drug-protein interaction, spectroscopic techniques

\section{Introduction}

Urease is a Ni-dependent enzyme widely synthesized by plants, fungi, bacteria, and some invertebrates. ${ }^{1-4}$ In the presence of ureases, the conversion of urea to ammonia $\left(\mathrm{NH}_{3}\right)$ and carbon dioxide $\left(\mathrm{CO}_{2}\right)$ is enhanced by one-hundred-trillion-fold. ${ }^{1,2,5,6}$ Urease is a pathogenic factor for the bacteria Helicobacter pylori, Proteus mirabilis,

*e-mail: josue@iqb.ufal.br; adefatima.geqob@gmail.com

Editor handled this article: José Walkimar M. Carneiro
Staphylococcus saprophyticus, and some plasmidcontaining Escherichia coli strains known to trigger urinary tract infection, kidney stone formation, pyelonephritis, hepatic encephalopathy, and ultimately hepatic coma. ${ }^{1,6-10}$ H. pylori can grow in the stomach ( $\mathrm{pH}$ lower than 2.0) due to the ability to excrete ureases. ${ }^{3,11}$ The increment of $\mathrm{pH}$ in the stomach due to $\mathrm{NH}_{3}$ accumulation contributes to gastric inflammation and the formation of duodenal and gastric ulcers and gastric adenocarcinoma and lymphoma. ${ }^{1-3}$ For these reasons, the development of urease inhibitors is an important tool for medical applications. ${ }^{12-14}$ 
Benzothiazoles, benzimidazoles, and derivatives have been used as precursors and/or platforms for obtaining a diverse category of pharmacological agents such as anti-bacterial, ${ }^{15-20}$ antifungal, ${ }^{16,17,20,21}$ antiallergic, ${ }^{22}$ antiviral, ${ }^{23-26}$ anticancer, ${ }^{27-34}$ antiprotozoal, ${ }^{35-38}$ leishmanicide ${ }^{39}$ and neuroprotective. ${ }^{40-42}$ For instance, riluzole (Figure 1, 1) is the only drug approved to treat amyotrophic lateral sclerosis, a neurodegenerative disease. ${ }^{40,41}$ In many studies the enzymatic evaluations are fundamental to establish these activities, such as inhibition of $\alpha$-amylase,,$^{4-45} \alpha$-glucosidade,,$^{43}$ and $\beta$-glucuronidade. ${ }^{46}$ A potent inhibitory effect of urease activity was reported for 2-aminobenzothiazole (Figure 1, 2), exhibiting a concentration of a drug required for $50 \%$ inhibition in vitro $\left(\mathrm{IC}_{50}\right)$ value of $28.88 \mathrm{mg} \mathrm{mL}^{-1}(79.7 \mu \mathrm{M})$ under the tested experimental conditions. ${ }^{47}$ Benzimidazole (Figure 1, 3) has an excellent anti-Staphylococcus aureus activity (minimal inhibitory concentration $(\mathrm{MIC})=0.39 \mu \mathrm{M}$ and minimum bactericidal concentration $(\mathrm{MBC})=0.78 \mu \mathrm{M})$ compared to that observed for ciprofloxacin $(\mathrm{MIC}=\mathrm{MBC}=0.39 \mu \mathrm{M})$, the positive control used for the antibacterial tests. ${ }^{19}$ Maribavir (Figure 1, 4), a benzimidazole ribonucleoside, has a prominent antihuman Cytomegalovirus activity by inhibiting a viral protein kinase known as UL97. ${ }^{24}$ In addition, maribavir possesses a favorable safety profile and excellent oral bioavailability. ${ }^{24,48-50}$ Omeprazole (Figure 1, 5) has been recognized to have both a bacteriostatic and bactericidal in vitro effect on the growth of H. pylori by inhibiting bacterial urease activity. ${ }^{51,52}$

Although many pharmacological properties for benzothiazoles and/or benzimidazoles are described there is no report about the potential activity against $H$. pylori, one of the most common causes of bacterial infections in human beings. H. pylori is responsible for gastritis, peptic ulcer, and gastric cancer. ${ }^{53} \mathrm{~A}$ variety of virulence factors has been proposed for $H$. pylori, such as motility, exotoxins, mucinase, adhesion, and urease activity. ${ }^{54}$ Urease is pivotal to $H$. pylori since it allows this bacterium to survive in the highly acidic gastric lumen, and consequently, to colonize the gastric mucosa. ${ }^{55,56}$ It has been estimated that ca. 10\% of the overall protein of such bacterium consists of urease. ${ }^{57}$ Urease activity is present in all $H$. pylori isolates, even though the levels of urease activity differ significantly between strains. ${ }^{58,59}$ Due to the importance of urease for $H$. pylori infection, this enzyme has been considered an active target to fight the bacterium. . $^{3,50}$

In 2015, we disclosed that among 18 benzothiazoles synthesized, 2-(pyridin-4yl)benzothiazole (BTA, Figure 1) is the most active jack bean urease inhibitor, exhibiting a typical mechanism of action of the mixed inhibitor. ${ }^{56}$ Due to its highlighted anti-ureolytic activity, we felt motivated to synthesize the benzimidazole-analog of BTA (named as BIA; Figure 1) and to investigate the interaction process with urease in order to understand better their inhibitory effects as well as the effect of changing the $\mathrm{S}$ (existing in BTA) atom by the -NH group (BIA). As part of the structural characterization, we elucidated crystal structures of BTA and BIA in new solid-state polymorphic forms. Binding and thermodynamic parameters, as well as changes in the native urease structure, were also determined to explore UV-Vis, molecular fluorescence, and circular dichroism in vitro conditions. We similarly performed a competitive assay with the substrate (urea) and the inhibitors (hydroxyurea and omeprazole) to evaluate the urease's preferential interaction site with BTA and BIA. Besides the experimental assay executed, theoretical studies on how BTA and BIA interact with urease were also conducted. Lastly, we determined the MIC values for both substances against seven $H$. pylori species.

\section{Results and Discussion}

\section{Synthesis analysis of BTA and BIA}

For the respective preparation of benzothiazole BTA and benzimidazole BIA, we carried out reactions<smiles></smiles><smiles>CC(C)Nc1nc2cc(Cl)c(Cl)cc2n1C1OC(CO)[C@@H](O)[C@H]1O</smiles>

Maribavir (4)

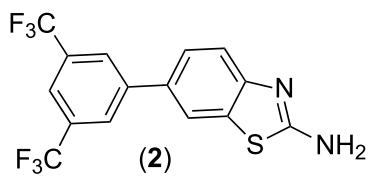

(2)

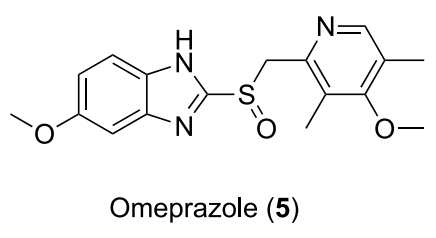<smiles>Oc1cccc(-c2nc3ccccc3[nH]2)c1</smiles>

(3)

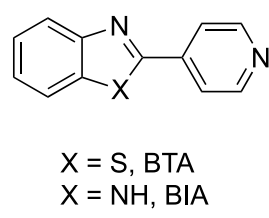

Figure 1. Benzothiazoles and benzimidazole of pharmaceutical interest. 


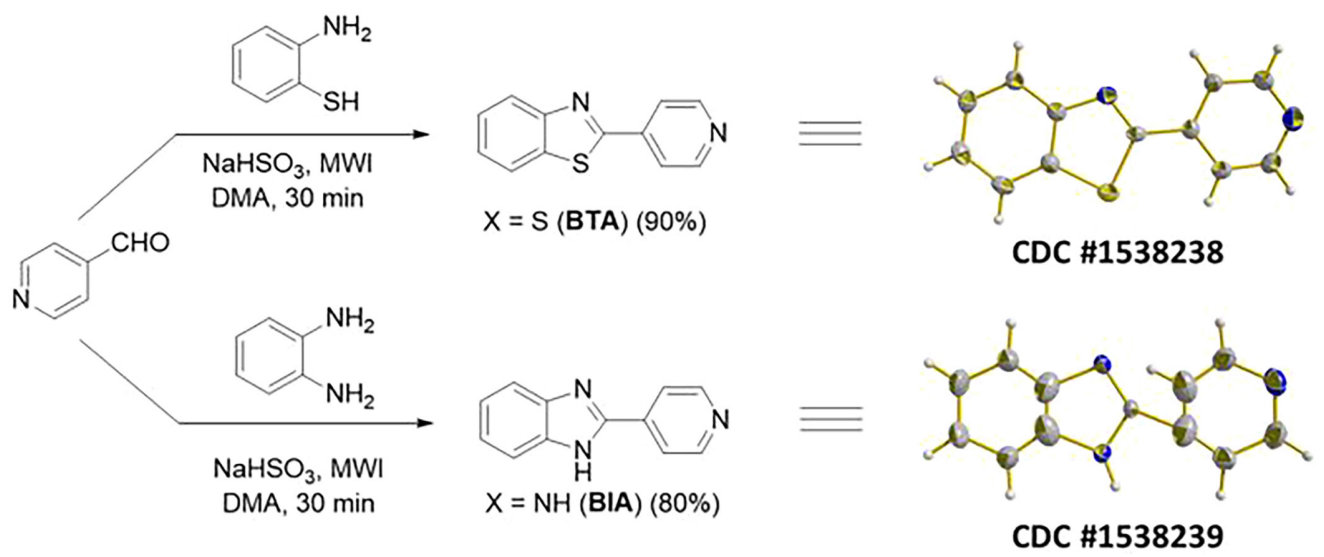

Scheme 1. Sodium bisulfite-catalyzed reaction for the synthesis of BTA and BIA under microwave irradiation (MWI). Reaction conditions and reagents: BTA: $o$-aminothiophenol (5.0 mmol), 4-pyridinecarboxaldehyde (5.5 mmol), $\mathrm{NaHSO}_{3}(10 \mathrm{mmol})$ and $N, N$-dimethylacetamide (DMA; $2.0 \mathrm{~mL}$ per $5.5 \mathrm{mmol}$ of aldehyde), $120^{\circ} \mathrm{C}$; BIA: $o$-phenylenediamine $(5.0 \mathrm{mmol})$, 4-pyridinecarboxaldehyde $(5.5 \mathrm{mmol}), \mathrm{NaHSO}_{3}(10 \mathrm{mmol})$ and $N, N$-dimethylacetamide (DMA; $2.0 \mathrm{~mL}$ per $5.5 \mathrm{mmol}$ of aldehyde), $80^{\circ} \mathrm{C}$.

of $o$-aminothiophenol or $o$-phenylenediamine with 4-pyridinecarboxaldehyde in the presence of sodium bisulfite $\left(\mathrm{NaHSO}_{3}\right)$ as a catalyst (Scheme 1). ${ }^{61}$ $N, N$-Dimethylacetamide (DMA) was used as a solvent in reactions carried out for 30 min under microwave irradiation (MWI) at different temperatures (120 and $80{ }^{\circ} \mathrm{C}$ for BTA and BIA, respectively; Scheme 1) ${ }^{61}$ Under our experimental conditions, $\mathrm{NaHSO}_{3}$-catalyzed reactions yielded BTA and BIA in 90 and $80 \%$, respectively.

The synthesized compounds were fully characterized using infrared (IR), ${ }^{1} \mathrm{H}$, and ${ }^{13} \mathrm{C}$ nuclear magnetic resonance (NMR) and mass spectrometry. Our research group ${ }^{61}$ previously synthesized BTA, and their spectroscopic data are available. The structures of BIA were confirmed by spectroscopic and mass spectrometry; the data is in accordance with those published by Moorthy and Neogi in $2011 .{ }^{62}$

\section{Crystal structure of BIA and BTA}

Compound BIA was crystallized in the orthorhombic space group Ibam with one-quarter of one molecule in the asymmetric unit. The entire molecule is generated if a mirror, two-fold axis, and inversion symmetry operations are applied to its asymmetric unit (Figure 2a). However, it is disordered over two occupancy site sets, with benzene and pyridyl rings overlaid (Figure 2a). Consequently, their imidazole moieties are not overlaid, but they are intertwined onto the molecular plane instead. Besides, the pyridyl moiety from each molecular orientation can also adopt two positions responsible for splitting its nitrogen over two sites of 0.25 occupancy (Figure 2a). The BIA molecule is planar, with a root-mean-square deviation (RMSD) of $0.973 \AA$ for all non-hydrogen atoms fitted onto the molecular leastsquare plane. To the best of our knowledge, this is the second crystal structure of BIA, which differs primarily from the first one for the $\mathrm{NH}$...N hydrogen-bonding pattern. In the previous structure (monoclinic $\mathrm{P} 2_{1} / n$, one molecule in the asymmetric unit) ${ }^{63}$ such hydrogen bonds are formed between imidazole and pyridyl moieties while such interactions occur in our crystal form between imidazole moieties themselves (Figure 2b). The pattern found in our structure even explains the disorder phenomenon found here since, to assemble it, the imidazole NH hydrogen can be equally bonded to both imidazole nitrogen atoms from the two molecular orientations.

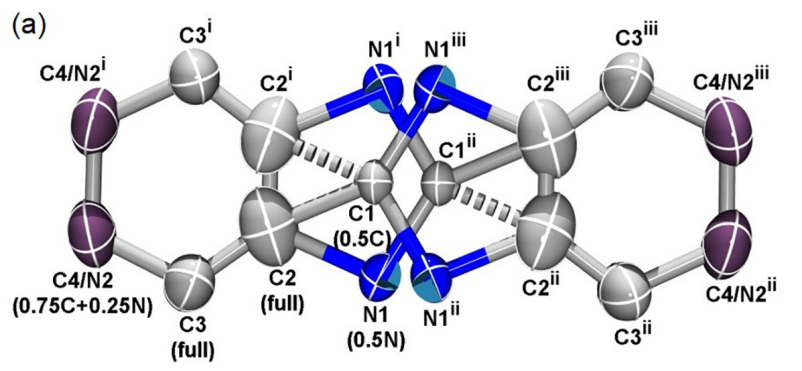

(b)

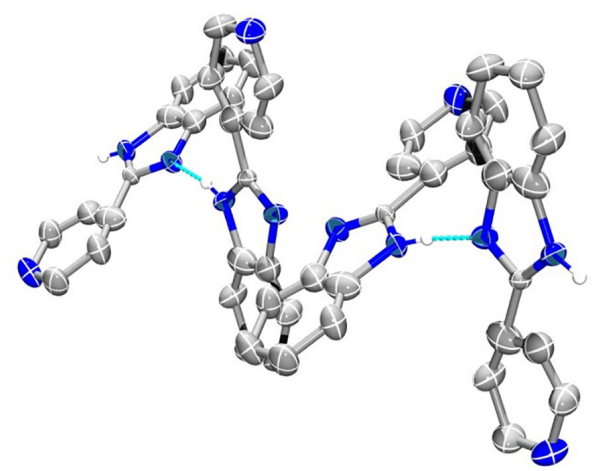

Figure 2. (a) $30 \%$ ellipsoid plot of the BIA molecule disordered over two occupancy site sets, whose benzene and pyridyl rings were found to be overlaid in this study. (b) One possible hydrogen bonding array in the crystal packing of BIA is determined here, with imidazole NH hydrogens covalently bonded to four imidazole nitrogen atoms equivalent to the four shown in (a). 
Furthermore, each pyridyl ring is also disordered over two occupancy site sets, resulting in a site occupancy factor (SOF) of 0.25 for N2, overlaid to C4 having an SOF of 0.75 (corresponding to 0.50 from benzene carbon plus 0.25 from pyridyl). Such additional pyridyl disorder is responsible for two possible bonds (one of them is a dashed gray stick) between this ring and the imidazole. Symmetry operators: (i) $\mathrm{x}, \mathrm{y},-\mathrm{z}$ (mirror); (ii) $1-\mathrm{x},-\mathrm{y}, \mathrm{z}$ (two-fold axis); (iii) $1-\mathrm{x},-\mathrm{y},-\mathrm{z}$ (inversion). One possible hydrogen bonding array in the crystal packing of BIA is determined in Figure 2b, with imidazole NH hydrogens covalently bonded to four imidazole nitrogen atoms equivalent to the four shown in Figure 2a.

The crystal structure of compound BTA was solved in the monoclinic space group $\mathrm{P} 2 / n$ with one and a half molecule in the asymmetric unit. The other half molecule is generated by inversion-symmetry. This molecule exhibits a disorder similar to that reported here for the crystal form of BIA, with two occupancy site sets almost overlaid through their benzene and pyridine rings (Figure S1a, Supplementary Information (SI) section). Both full and $50 \%$ occupancy molecules are nearly completely planar, with an RMSD of 0.0227 and $0.0292 \AA$ for all nonhydrogen atoms fitted in their least-square planes. An input for a crystal structure of BTA is found in the CSD (CSD reference code AYIRAD, monoclinic $\mathrm{P} 2_{1} / c$, one molecule in the asymmetric unit). The inspection of this structure reveals that we have found a new BTA polymorph. Besides the differences in the unit cell metrics and the number of molecules per unit cell, these polymorphs also differ for their molecular $\pi$-stacking pattern (Figures S1b, S1c, SI section).

\section{Enzyme activity assays}

The screening experiments performed with the compounds-test at $1.6 \mathrm{mM}$ revealed that the benzothiazole BTA was 1.6-fold more efficient against the jack bean urease than its benzimidazole analogous BIA (Table 1). Likewise, the concentration of BTA necessary to inhibit the urease activity by $50 \%\left(\mathrm{IC}_{50}\right)$ was 2.8 -fold lower than that of BIA and also lower than the $\mathrm{IC}_{50}$ of hydroxyurea (HU), a reference urease inhibitor (Table 1). One should note that the maximum inhibition of urease caused by BTA is on average $65 \%$ when used at concentrations equal to or higher than $1.5 \mathrm{mM}$, indicating that the inhibition reached a plateau.

Kinetics experiments were carried out solely with BIA as the data for BTA under the same experimental conditions were already reported by our group. ${ }^{61}$ As observed for BTA, the urease inhibition mechanism shown by BIA is typical
Table 1. Effect of the benzothiazole BTA and the benzimidazole analog BIA on the activity of jack bean urease. Results correspond to the means of four independent experiments performed with four replicates

\begin{tabular}{lcc}
\hline Compound & Urease inhibition ${ }^{\mathrm{a}} / \%$ & $\mathrm{IC}_{50} \mathrm{~b} / \mathrm{mM}$ \\
\hline BTA & 63 & $0.77 \pm 0.062$ \\
BIA & 39 & $2.14 \pm 0.19$ \\
HU & 61 & $0.88 \pm 0.059$ \\
\hline
\end{tabular}

${ }^{\mathrm{a} C o m p o u n d s-t e s t ~ w e r e ~ u s e d ~ a t ~ a ~ f i n a l ~ c o n c e n t r a t i o n ~ o f ~} 1.6 \mathrm{mM}$; ${ }^{\mathrm{b}}$ compounds-test were used in the range of $0.5-2.0 \mathrm{mM}$ and the results expressed as the mean \pm standard deviation. $\mathrm{IC}_{50}$ : concentration of a drug required for $50 \%$ inhibition in vitro; BTA: benzothiazole; BIA: benzimidazole; HU: hydroxyurea.

of mixed inhibitors (Table 2; Figure 3). Therefore, the benzimidazole BIA is able to bind to the enzyme active site to form a urease-BIA complex or an allosteric site (ureaseurea-BIA complex). The inhibitor dissociation constants for BIA were $2.1 \pm 0.47 \mathrm{mM}\left(\mathrm{K}_{\mathrm{i}}\right)$ and $1.45 \pm 0.29 \mathrm{mM}\left(\mathrm{K}_{\mathrm{i}}{ }^{\prime}\right)$. Such values indicate that the affinity of BIA to an allosteric urease site is higher than that to the enzyme active site.

Table 2. Effect of BIA on the kinetics of jack bean type III urease

\begin{tabular}{lcc}
\hline BIA / $\mathrm{mM}$ & $\mathrm{K}_{\mathrm{M}}$ or $\mathrm{K}_{\mathrm{M}(\mathrm{app})} / \mathrm{mM}$ & $\begin{array}{c}\mathrm{V}_{\max } \text { or } \mathrm{V}_{\max (\mathrm{app})} / \\
\left(\mu \mathrm{mol} \mathrm{NH}_{4}^{+} \mathrm{min}^{-1} \mathrm{mg}^{-1} \text { prot }\right)\end{array}$ \\
\hline 0.0 & 5.6 & 7.4 \\
1.0 & 5.3 & 4.7 \\
2.0 & 5.1 & 3.1 \\
\hline
\end{tabular}

$\mathrm{K}_{\mathrm{M}}$ : measure of how easily the substrate can saturate the enzyme; $\mathrm{V}_{\max }$ : maximum rate of an enzyme-catalyzed reaction; app: apparent; $\mathrm{K}_{\mathrm{M}(\text { app) }}$ and $\mathrm{V}_{\max (\text { app) }}$ are the apparent $\mathrm{K}_{\mathrm{M}}$ and apparent $\mathrm{V}_{\max }$, respectively, and were determined from reactions containing urease, urea, and BIA (benzimidazole).

Interaction of BTA and BIA with urease by fluorescence and UV-Vis

A steady-state spectrofluorimetric titration based on intrinsic protein fluorescence was explored to evaluate the interaction between urease's active antiureolytic compounds BTA and BIA. The fluorescence intensity variation of urease $(1 \mu \mathrm{M})$ upon BTA addition is shown in Figure 4a. Trp presents high sensitivity to microenvironment polarity changes; thus, based on urease fluorescence, maximum emission located at $334 \mathrm{~nm}$ and indicates that the Trp residues are partially protected from water in native protein structure. ${ }^{64}$

In Figure 4a, a redshift of urease fluorescence maximum emission (from 334 to $344 \mathrm{~nm}$ ) could be related to conformational changes induced by the interaction process of BTA with urease, which leads to the increasing polarity around Trp residues. ${ }^{65}$ Similar results were observed 

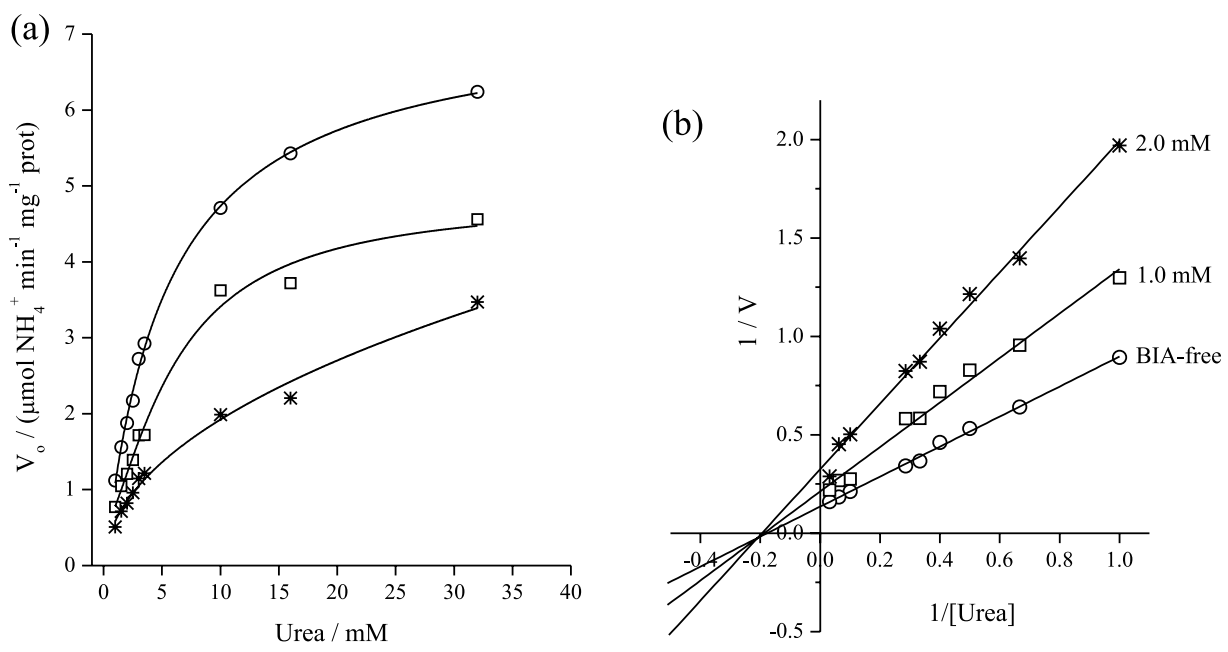

Figure 3. (a) Michaelis-Menten hyperbola and (b) Lineweaver-Burk plot for jack bean urease as a function of increased concentration of BIA. Reactions containing varied urea concentrations (1.0 to $32 \mathrm{mM}$ ) were carried out in the absence (BIA-free) or BIA presence at the indicated concentrations.
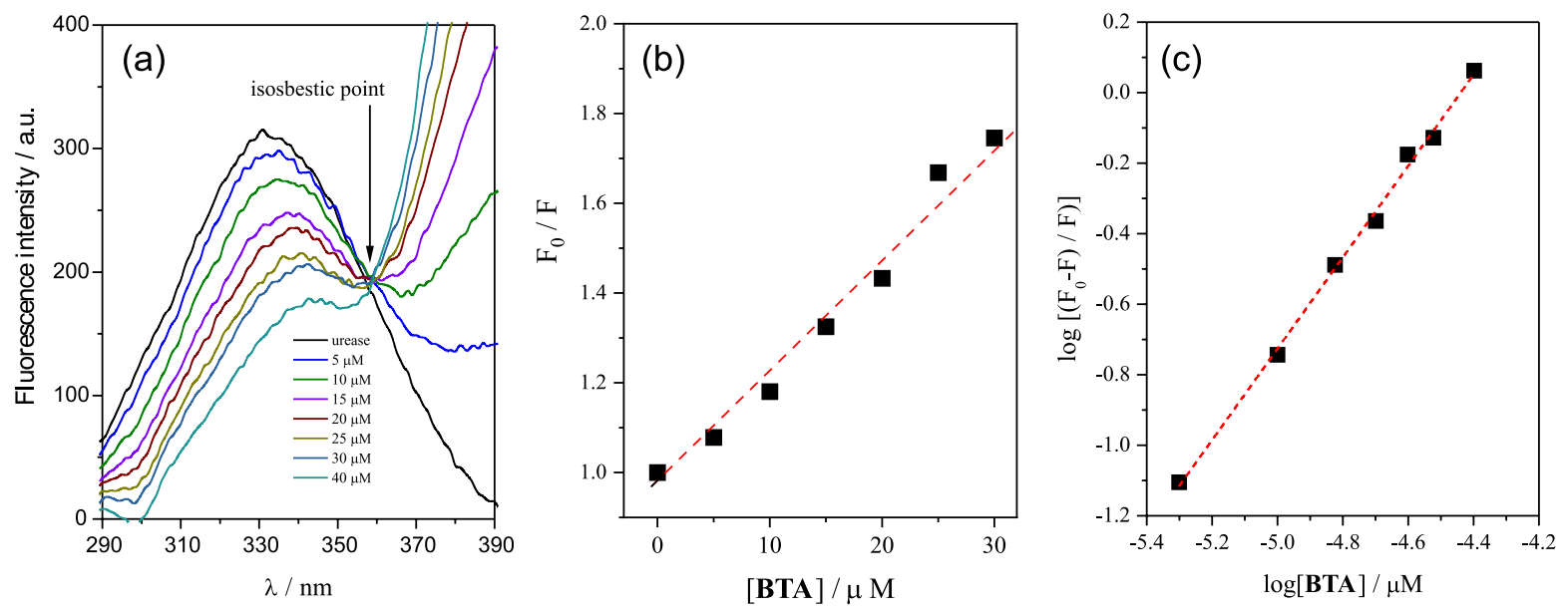

Figure 4. (a) Emission spectral profile of urease $(1 \mu \mathrm{M})$ at different concentrations of BTA $(5-40 \mu \mathrm{M})$ at $\mathrm{pH} 7.4$ and $28^{\circ} \mathrm{C}$; (b) Stern-Volmer quenching plot; (c) double logarithmic curve to binding constant calculation.

for BIA associated with a redshift from 334 to $340 \mathrm{~nm}$ (Figure S2, SI section). Besides, a well-defined isosbestic point was observed for BTA at $359 \mathrm{~nm}$ while, for BIA, it was verified at $343 \mathrm{~nm}$, with lower resolution.

The fluorescence quenching associated with the interaction process can be described by the Stern-Volmer constant, calculated based on equation 1 :

$\frac{\mathrm{F}_{0}}{\mathrm{~F}}=1+\mathrm{K}_{\mathrm{SV}}[\mathrm{Q}]$ or $\frac{\mathrm{F}_{0}}{\mathrm{~F}}=1+\mathrm{k}_{\mathrm{q}} \tau_{0}[\mathrm{Q}]$

where $F_{0}$ and $F$ are the fluorescence intensities in the absence and presence of the quencher at concentration [Q], respectively; $\mathrm{K}_{\mathrm{SV}}$ is the Stern-Volmer constant; $\mathrm{k}_{\mathrm{q}}$ is the maximum rate constant for diffusional quenching bimolecular constant in biopolymer systems $\left(2.0 \times 10^{10} \mathrm{M}^{-1} \mathrm{~s}^{-1}\right)$, and $\tau_{0}$ is the average lifetime $\left(10^{-8} \mathrm{~s}\right)$. The binding constant $\left(\mathrm{K}_{\mathrm{b}}\right)$ was calculated according to equation 2 : $\log \left(\frac{\mathrm{F}_{0}-\mathrm{F}}{\mathrm{F}}\right)=\log \mathrm{K}_{\mathrm{b}}+n \log [\mathrm{Q}]$

where $n$ is the number of binding sites. Figures $4 \mathrm{~b}$ and $4 \mathrm{c}$ show linearization of the equations 1 and 2, respectively, to calculate the binding parameters $\mathrm{K}_{\mathrm{sV}}, \mathrm{K}_{\mathrm{b}}$, and $n$. Thus, the temperature effect was evaluated on the interaction of BTA and BIA with urease. The linear profile of the $\mathrm{K}_{\mathrm{Sv}}$ plot (Figure $4 b$ ) indicates that the accessibility of Trp residues to the inhibitor slightly differs. ${ }^{66}$ The temperature dependence of $\mathrm{K}_{\mathrm{SV}}$ values was used to determine the preferential quenching mechanism. Binding and thermodynamics parameters of urease interaction with evaluated compounds are described in Table 3.

Dynamic quenching is indicated when $\mathrm{K}_{\mathrm{Sv}}$ values increase with temperature since higher temperatures lead to a larger diffusion coefficient and a higher number of collisions between the fluorophore and the 
Table 3. Binding and thermodynamics parameters of urease interaction with BTA and BIA at different temperatures

\begin{tabular}{|c|c|c|c|c|c|c|c|c|c|c|}
\hline \multirow[b]{2}{*}{ Compound } & \multirow[b]{2}{*}{ Temperature / K } & \multicolumn{3}{|c|}{ Stern-Volmer constant } & \multicolumn{3}{|c|}{ Binding parameter } & \multicolumn{3}{|c|}{ Thermodynamic parameter } \\
\hline & & $\mathrm{K}_{\mathrm{SV}} / 10^{4} \mathrm{M}^{-1}$ & $\mathrm{r}$ & $\begin{array}{c}\mathrm{k}_{\mathrm{q}} / \\
\left(10^{12} \mathrm{M}^{-1} \mathrm{~s}^{-1}\right)\end{array}$ & $\mathrm{K}_{\mathrm{b}} / 10^{4} \mathrm{M}^{-1}$ & $n$ & $\mathrm{r}$ & $\begin{array}{c}\Delta \mathrm{G} / \\
\left(\mathrm{kJ} \mathrm{mol}^{-1}\right)\end{array}$ & $\begin{array}{c}\Delta \mathrm{H} / \\
\left(\mathrm{kJ} \mathrm{mol}^{-1}\right)\end{array}$ & $\begin{array}{c}\Delta \mathrm{S} / \\
\left(\mathrm{J} \mathrm{K} \mathrm{mol}^{-1}\right)\end{array}$ \\
\hline \multirow{3}{*}{ BTA } & $293\left(20^{\circ} \mathrm{C}\right)$ & $2.80 \pm 0.10$ & 0.9938 & 2.80 & $4.41 \pm 1.85$ & $1.05 \pm 0.03$ & 0.9886 & -25.94 & \multirow{3}{*}{+80.37} & \multirow{3}{*}{+362.83} \\
\hline & $301\left(28^{\circ} \mathrm{C}\right)$ & $2.62 \pm 0.06$ & 0.9903 & 2.62 & $9.23 \pm 1.99$ & $1.12 \pm 0.03$ & 0.9984 & -28.84 & & \\
\hline & $309\left(36^{\circ} \mathrm{C}\right)$ & $2.55 \pm 0.11$ & 0.9907 & 2.55 & $24.4 \pm 2.13$ & $1.22 \pm 0.03$ & 0.9935 & -31.75 & & \\
\hline \multirow{3}{*}{ BIA } & $293\left(20^{\circ} \mathrm{C}\right)$ & $2.67 \pm 0.15$ & 0.9861 & 2.67 & $97.2 \pm 5.44$ & $1.31 \pm 0.02$ & 0.9778 & -33.27 & \multirow{3}{*}{-93.55} & \multirow{3}{*}{-205.75} \\
\hline & $301\left(28^{\circ} \mathrm{C}\right)$ & $2.58 \pm 0.22$ & 0.9810 & 2.58 & $23.6 \pm 1.32$ & $1.20 \pm 0.02$ & 0.9634 & -31.62 & & \\
\hline & $309\left(36^{\circ} \mathrm{C}\right)$ & $2.47 \pm 0.12$ & 0.9842 & 2.47 & $13.4 \pm 0.75$ & $1.17 \pm 0.01$ & 0.9689 & -29.98 & & \\
\hline
\end{tabular}

$\mathrm{K}_{\mathrm{SV}}$ : Stern-Volmer constant; $\mathrm{k}_{\mathrm{q}}$ : maximum rate constant for diffusional quenching bimolecular constant in biopolymer systems; $\mathrm{K}_{\mathrm{b}}$ : binding constant; $n$ : binding site number; r: linear correlation coefficient; $\Delta \mathrm{G}$ : Gibbs free energy; $\Delta \mathrm{H}$ : enthalpy variation; $\Delta \mathrm{S}$ : entropy variation; BTA: benzothiazole; BIA: benzimidazole.

quencher ${ }^{67}$ When the $\mathrm{K}_{\mathrm{Sv}}$ values decrease with increasing temperatures, it indicates a static quenching since higher temperatures affect the stability of the protein-ligand complex. $\mathrm{K}_{\mathrm{Sv}}$ values presented a tendency of decreasing with the increase in temperature for both evaluated compounds (Table 3 ); thus, the interaction process among BTA and BIA with urease can occur possibly through the static quenching mechanism. This mechanism was confirmed from the bimolecular quenching constant $\left(\mathrm{k}_{\mathrm{q}}\right)$ values, which were higher than the limiting diffusional constant $\left(2.0 \times 10^{10} \mathrm{M}^{-1} \mathrm{~s}^{-1}\right)^{68}$ (Table 3).

Additionally, to confirm the quenching mechanism, UV-Vis experiments were performed (Figure 5). In the UV-Vis spectral evaluation, the complex urease-BTA absorbance at the maximum wavelength $\left(\mathrm{A}_{\text {complex }}=0.287\right)$ differed from the sum of the free BTA and free urease absorbance $\left(\mathrm{A}_{\mathrm{BTA}}+\mathrm{A}_{\text {urease }}=0.270\right)$, evidence that there was no additive effect of the Beer law. Furthermore, the spectrum resulting from the subtraction of the supramolecular complex spectrum (urease-BTA) and the free urease spectrum did not overlap the free BTA spectrum,

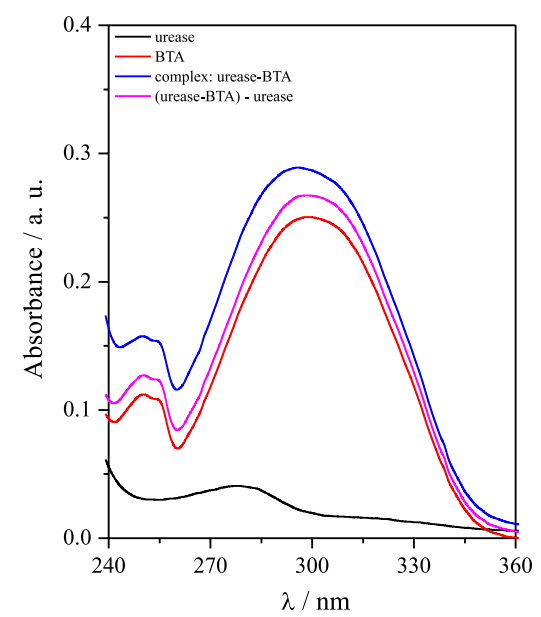

Figure 5. UV-Vis absorption spectra of urease $(3 \mu \mathrm{M})$, BTA $(15 \mu \mathrm{M})$, urease-BTA complex, and (urease-BTA) - urease at pH 7.4 and $28{ }^{\circ} \mathrm{C}$. confirming the existence of an interaction between the compound and urease ${ }^{69}$ Therefore, complex formation occurred with different spectroscopic properties of the ligand and free protein, indicating that a change of the ground state of the ligand occurred. These results are the subsidy for the quenching mechanism classification. Since changes occurred in the ground state due to the complex formation, the process occurred by static quenching, confirming the results by molecular fluorescence. Similar results were observed for the compound BIA (Figure S3, SI section).

Ligand affinity with urease is a relevant parameter for the protein-ligand interaction study, which can help elucidate the enzymatic inhibition process. Binding constant $\left(\mathrm{K}_{\mathrm{b}}\right)$ values can express this parameter and the number of sites occupied $(n)$ by the ligand in the urease structure. The binding constant of $9.23 \times 10^{4} \mathrm{M}^{-1}$ (BTA) and $23.6 \times 10^{4} \mathrm{M}^{-1}(\mathrm{BIA})$ at $28{ }^{\circ} \mathrm{C}$ (Table 3) indicate that there is high interaction between the metalloenzyme and benzimidazole compared to benzothiazole. However, with the temperature increase $\left(36^{\circ} \mathrm{C}\right)$, an inversion in enzyme affinity occurred, and BTA has a higher $\mathrm{K}_{\mathrm{b}}$ value than BIA.

The $\mathrm{K}_{\mathrm{b}}$ values obtained for BTA and BIA interaction with urease are concordant with the binding constant of urease with other species, as $(R)-(+)$-usnic acid $\left(35.5 \times 10^{5} \mathrm{M}^{-1}\right.$ at $\left.30^{\circ} \mathrm{C}\right),{ }^{70}$ Biginelli adducts $\left(1.44 \times 10^{2}\right.$ to $\left.5.25 \times 10^{6} \mathrm{M}^{-1}\right){ }^{71}$ pentachlorophenol $\left(3.85 \times 10^{3} \mathrm{M}^{-1}\right.$ at $\left.32{ }^{\circ} \mathrm{C}\right){ }^{72} \mathrm{~K}_{2} \mathrm{Cr}_{2} \mathrm{O}_{7}\left(1.96 \times 10^{4} \mathrm{M}^{-1}\right.$ at $\left.29{ }^{\circ} \mathrm{C}\right),{ }^{73}$ and $\mathrm{Cu}^{\mathrm{II}}\left(3.89 \times 10^{5} \mathrm{M}^{-1}\right.$ at $37{ }^{\circ} \mathrm{C}$, when $\left.\left[\mathrm{Cu}^{\mathrm{II}}\right]<16 \mu \mathrm{M}\right) .{ }^{74}$ The average of the binding site number $(n)$ varied from 1.13 (BTA) to 1.22 (BIA), considering the temperature range assessed. Therefore, the interaction process among these ligands and urease at a ratio of 1:1 (or near this value).

The distinct profile of $\mathrm{K}_{\mathrm{b}}$ variation for BTA and BIA with temperature can be attributed to the forces that govern the interaction process. Hydrogen bonds, van der 
Waals forces, electrostatic and hydrophobic interactions are the non-covalent forces that contribute to the stability of the ligand-protein bond. ${ }^{72}$ Thus, the interaction process at different temperatures allowed calculating the thermodynamic parameters and established the main forces involved in the protein-ligand interaction beyond the spontaneity tendency. Thermodynamic parameters (enthalpy $(\Delta \mathrm{H})$ and entropy $(\Delta \mathrm{S})$ variations, Table 3) were calculated according to the linearization of the Van't Hoff equation (Figure S4, SI section), whereas the heat of reaction does not change with temperature:

$\ln \mathrm{K}_{\mathrm{b}}=-\frac{\Delta \mathrm{H}}{\mathrm{R}}\left[\frac{1}{\mathrm{~T}}\right]+\frac{\Delta \mathrm{S}}{\mathrm{R}}$

where $\mathrm{T}$ is the temperature in Kelvin, and $\mathrm{R}$ is the gas constant. Therefore, to evaluate the process spontaneity, Gibbs free energy $(\Delta \mathrm{G})$ was calculated by equation 4 :

$\Delta \mathrm{G}=\Delta \mathrm{H}-\mathrm{T} \Delta \mathrm{S}$

According to Ross and Subramanian ${ }^{75}$ and Santana et al. ${ }^{76}$ hydrophobic interactions are fundamental in complex stability between compound BTA and urease, since $\Delta \mathrm{H}>0$ and $\Delta \mathrm{S}>0$, while van der Waals forces and hydrogen bonds are crucial to the binding of BIA to the enzyme, since $\Delta \mathrm{H}<0$ and $\Delta \mathrm{S}<0$. The difference in the force types involved in the interaction process between the evaluated compounds can be justified by the orientation of the pyridine ring and the benzothiazole and benzimidazole moieties' ability to form distinct interactions in the active site, as demonstrated in theoretical studies. In addition, negative values of $\Delta G$ were observed; therefore, the interaction process between compounds and urease is spontaneous.

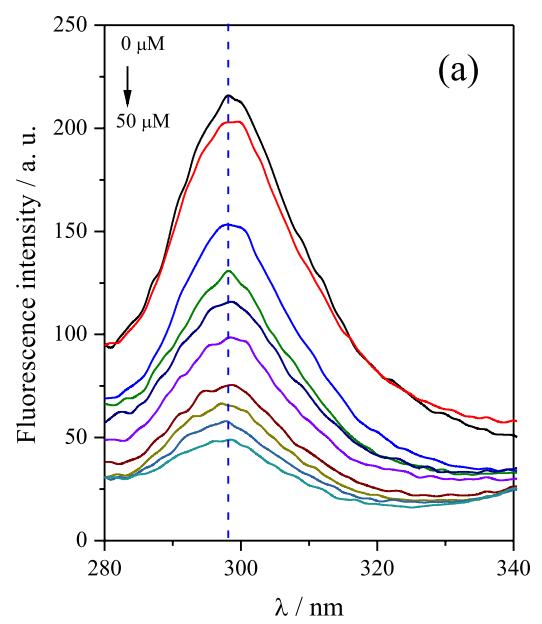

Urease conformational investigation: synchronous fluorescence studies

Synchronous fluorescence has several advantages, such as sensitivity, spectral simplification, and spectral bandwidth reduction. Thus, synchronous fluorescence was performed to evaluate the influence of non-covalent forces on the native urease structure and microenvironment polarity related to tyrosine (Tyr) and tryptophan (Trp) residues. Stern-Volmer constant $\left(\mathrm{K}_{\mathrm{sv}}\right)$ based on $\Delta \lambda=15 \mathrm{~nm}$ (tyrosine) and $\Delta \lambda=60 \mathrm{~nm}$ (tryptophan) ${ }^{77}$ was the parameter used to evaluate interaction process. Figure 6 shows the synchronous fluorescence spectra of Tyr and Trp residues in urease with various amounts of BTA, respectively. Similar results were obtained for BIA (Figure S5, SI section). Table 4 presented synchronous fluorescence binding parameters for the compounds evaluated with urease.

The spectra profile showed an emission maximum shift for both compounds evaluated against urease (Figure 6 and Table 4). The shifts were more pronounced for Trp residues than Try, probably because tyrosine residues are less sensitive to changes in polarity of the medium (water solvent) than tryptophan. ${ }^{64}$ Positive variations indicate an increase in polarity of the microenvironment, and negative variations are associated with polarity reduction; both processes allow description changes in the original protein structure. $^{78}$

According to the $\mathrm{K}_{\mathrm{SV}}$ values (quantitative evaluation), Tyr residues were more affected than Trp (Table 4). This fact is associated with the proximity of the urease catalytic site. Tyr410 and Tyr544 residues are neighbors of His409 and His545, respectively, which are in the catalytic center of the enzyme, coordinated to nickel atoms, ${ }^{70,71,79}$ while tryptophan residues close to the urease catalytic site are Trp495 and Trp648. Indeed, the tyrosine residues had

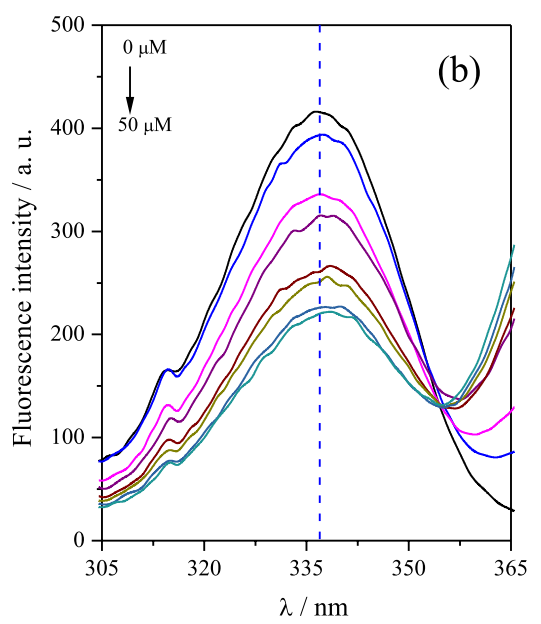

Figure 6. Urease $(1.0 \mu \mathrm{M})$ synchronous fluorescence spectra upon an addition of increasing concentrations of BTA $(2.5-50 \mu \mathrm{M})$ in $\mathrm{pH} 7.4$ and $28{ }^{\circ} \mathrm{C}$, monitoring (a) $\Delta \lambda=15 \mathrm{~nm}$ (Tyr) and (b) $\Delta \lambda=60 \mathrm{~nm}$ (Trp). 
Table 4. Synchronous fluorescence binding parameters for BTA and BIA with urease

\begin{tabular}{|c|c|c|c|c|}
\hline \multirow{2}{*}{ Compound } & \multirow{2}{*}{$\Delta \lambda / \mathrm{nm}$} & \multicolumn{2}{|c|}{ Stern-Volmer parameter } & \multirow{2}{*}{$\begin{array}{c}\text { Maximum wavelength } \\
\text { emission shift }^{\mathrm{a}} / \mathrm{nm}\end{array}$} \\
\hline & & $\mathrm{K}_{\mathrm{SV}} / 10^{4} \mathrm{M}^{-1}$ & $\mathrm{r}$ & \\
\hline \multirow{2}{*}{ BTA } & 15 & $7.50 \pm 0.26$ & 0.9971 & +1 \\
\hline & 60 & $2.09 \pm 0.16$ & 0.9864 & +3 \\
\hline \multirow{2}{*}{ BIA } & 15 & $8.34 \pm 0.32$ & 0.9964 & -1 \\
\hline & 60 & $1.58 \pm 0.12$ & 0.9956 & +6 \\
\hline
\end{tabular}

The reference employed was the free urease. $\lambda$ : wavelength; $\mathrm{K}_{\mathrm{Sv}}$ : Stern-Volmer constant; BTA: benzothiazole; BIA: benzimidazole; r: linear correlation coefficient.

their microenvironment changed more significantly than tryptophan in the interaction process. Therefore, these results explain BTA and BIA as a mixed inhibitors, corroborating the kinetic enzymatic assay.

\section{Urease conformational investigation: circular dichroism (CD) studies}

$\mathrm{CD}$ analyses were performed to investigate the possible influence of BTA and BIA on the secondary structure changes of urease. Figure $7 \mathrm{a}$ exhibits broadband, with characteristic absorption at 208 and $220 \mathrm{~nm}$ due to electronic transitions $\pi \rightarrow \pi^{*}$ and $n \rightarrow \pi^{*}$ of the urease polypeptide chain, associated with the $\alpha$-helical structure of proteins. ${ }^{80}$ The $\mathrm{CD}$ result was expressed as mean residual ellipticity (MRE, deg $\mathrm{cm}^{2} \mathrm{dmol}^{-1}$ ), calculated by:

$\mathrm{MRE}=\frac{\theta_{\mathrm{obs}}}{10 \mathrm{nlC}_{\mathrm{p}}}$

where $\theta_{\text {obs }}$ is the CD in milli-degree, $\mathrm{n}$ is the number of amino acid residues of urease ( 840 for a subunit), 1 is the path length of the cell $(0.1 \mathrm{~cm})$, and $\mathrm{C}_{\mathrm{p}}$ is the molar concentration of urease. ${ }^{81}$ The Raussens method ${ }^{82}$ calculated protein secondary structure content from CD spectra (Figure 7b).

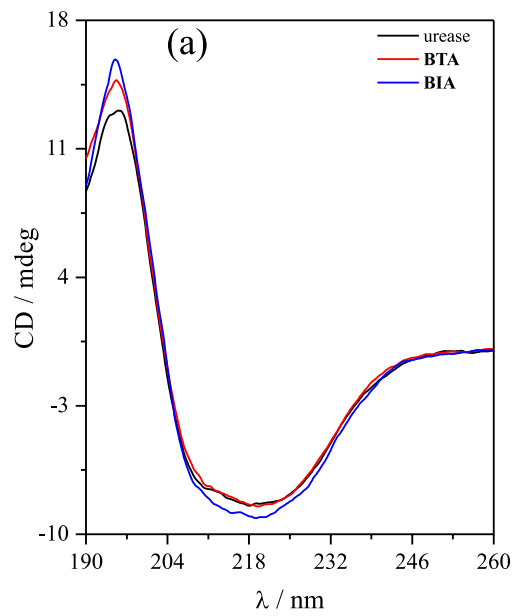

Free urease (in the absence of ligands) presented $35.5 \%$ of $\alpha$-helical, $12 \%$ of $\beta$-sheet, $17.7 \%$ of a turn, and $34.8 \%$ of random-coil (Figure 7b). The interaction did not change the turn content in the secondary protein structure with different ligands. In the presence of BTA and BIA, $\alpha$-helical increased 45.3 and $44 \%$, respectively, evidencing that all compounds evaluated modified the secondary structure of the protein. The $\alpha$-helical content of urease variation in the presence of BTA and BIA was contrasting with $\mathrm{Cr}^{\mathrm{VI}},{ }^{72} \mathrm{Cu}^{\mathrm{II}},{ }^{74}$ and silver nanoparticles,${ }^{83}$ where there was a reduction in $\alpha$-helical percentage. The $\beta$-sheet secondary protein structure content decreased only in the presence of BIA. Based on CD results, it is possible to justify the differentiation in the urease secondary structure variations, probably due to the forces of each ligand involved in the interaction process since both (BTA and BIA) are mixed inhibitors. Finally, the theoretical studies section assist in understanding the influence of each ligand on the active site and the possible interactions that justify the changes observed in CD studies.

\section{Competition assay}

BTA and BIA interact by synchronous fluorescence, preferably in the urease catalytic site, since there is a more

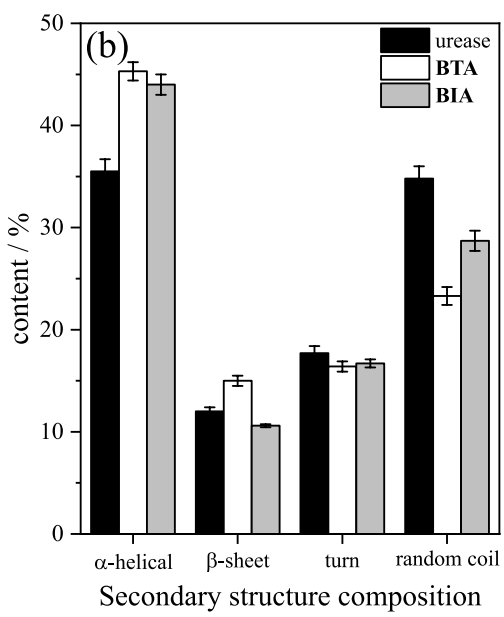

Figure 7. (a) CD analysis spectra, and (b) secondary structure composition of urease (based on urease subunit) in the absence and presence of BTA and BIA. Urease and evaluated compounds at 6 and $12 \mu \mathrm{M}$, respectively, at $\mathrm{pH} 7.4\left(20^{\circ} \mathrm{C}\right)$. 
significant change in tyrosine residues microenvironment polarity (Tyr410 and Tyr544), which is close to the binding site. ${ }^{70,71}$ Thus, the influence of substrate (urea) and competitive inhibitor (hydroxyurea) in the interaction process of urease with BTA and BIA was evaluated by a competition assay. The ratio of the binding constant in the presence $\left(\mathrm{K}_{\mathrm{b}}{ }^{\prime}\right)$ and absence $\left(\mathrm{K}_{\mathrm{b}}\right)$ of the competitor was used as the comparative parameter. When $\mathrm{K}_{\mathrm{b}}, / \mathrm{K}_{\mathrm{b}}>1$, the complex is favored, and the opposite behavior occurs when $\mathrm{K}_{\mathrm{b}}$ ' / $\mathrm{K}_{\mathrm{b}}<1$, disfavoring urease and complex formation (Table 5).

Table 5. Binding constants ratio in the absence $\left(\mathrm{K}_{\mathrm{b}}\right)$ and presence $\left(\mathrm{K}_{\mathrm{b}}{ }^{\prime}\right)$ of substrate and urease inhibitors

\begin{tabular}{lcc}
\hline & \multicolumn{2}{c}{ Binding constant ratio $\left(\mathrm{K}_{\mathrm{b}}{ }^{\prime} / \mathrm{K}_{\mathrm{b}}\right)$} \\
\cline { 2 - 3 } Compound & Substrate & Competitor \\
\cline { 2 - 3 } & Urea & $\mathrm{HU}$ \\
\hline BTA & 0.38 & 0.60 \\
BIA & 0.68 & 0.02 \\
\hline
\end{tabular}

$\mathrm{K}_{\mathrm{b}}$ ': binding constant in the presence of $25 \mu \mathrm{M}$ of substrate or inhibitor, urease $(1.0 \mu \mathrm{M})$, BTA $(2.5-40 \mu \mathrm{M})$, and BIA $(1.0-20 \mu \mathrm{M})$; HU: hydroxyurea; BTA: benzothiazole; BIA: benzimidazole.

In general, the binding constant decreases in the presence of substrate and competitive inhibitor hydroxyurea $\left(\mathrm{K}_{\mathrm{b}}{ }^{\prime} / \mathrm{K}_{\mathrm{b}}<1\right)$, indicating that BTA and BIA interact in the enzyme's active site, corroborating the results of synchronous fluorescence and the kinetic enzymatic assay.

\section{Theoretical studies}

For docking protocol validation, a self-docking experiment was performed, where the co-crystallized acetohydroxamic acid (HAE) was removed from the ligand-binding domain of the jack bean urease, and a flexibly re-docking was then performed using the four scoring functions from the Gold software.$^{84}$ For all of them, the re-docked HAE-enzyme complex revealed the same coordination with two nickel ions (cofactors) and intermolecular interactions with key residues in the protein's active site compared to the crystallographic complex (Figure S6, SI section). ${ }^{71}$ The best RMSD value was obtained by using the ChemPLP function $(0.212 \AA)$.

After protocol validation, molecular docking was performed for the active compounds BTA and BIA, whose best docking conformations were evaluated to understand the binding modes (Figure 8). The results showed a similarity in the fitting-in mechanism at the active site. For both compounds, the orientation of the pyridine ring in the active site plays an essential role in the coordination involving the free electron pair of the pyridine nitrogen atom and Ni metals, resulting in stable ligand-enzyme complexes, which appear to be responsible for their urease inhibition. Subsequently, the predicted binding conformations showed the formation of interactions with key residues, as hydrophobic contacts between His593 and benzimidazole or benzothiazole moieties, and carbon-hydrogen bonding between Asp633 and the pyridine ring. This aryl ring is involved in other interactions with His519 and carbamylated lysine KCX490 residues, including van der Waals for BIA, and $\pi-\pi$ stacking and carbon-hydrogen bonding for the analogue BTA. In addition, the modified cysteine residue CME592 present in the histidine-rich region of the target interacts with BIA and BTA via a conventional hydrogen bond and $\pi$-sulfur contact, respectively.

For the BIA derivative, the binding conformation showed that further stability was due to the formation of additional interactions, including $\pi$-alkyl interactions between Ala440 and the benzimidazole moiety, van der Waals contacts involving Arg439, His407, His545, His492, and Gly550 residues, and $\pi$-anion interactions between Asp633 and the pyridine ring. An additional carbonhydrogen bond was observed between the same aromatic group and His404 (Figures 8a and 8c). On the other hand, the BTA derivative showed $\pi$-alkyl and conventional hydrogen bonds between benzothiazole moiety and Leu523 and Thr522 residues. Besides, the pyridine ring is involved in van der Waals contacts with Gln635 and His492, and carbon-hydrogen bond with Gly550 (Figures 8b and $8 d)$. In general, docking results are in agreement with thermodynamic parameters $(\Delta \mathrm{H}$ and $\Delta \mathrm{S})$ experimentally calculated for each compound (Table 3 ) and the CD studies.

In order to understand the dynamic properties and stability of BIA- and BTA-urease complexes, molecular dynamic (MD) simulations were performed using the docking poses as the initial conformations as a reference. Figure 9a represents the RMSD plots for the backbone $\mathrm{C} \alpha$ atoms of urease in the presence and absence of BIA and BTA. The RMSD of native urease showed few fluctuations until the end of the simulation, and, in the presence of both ligands, the enzyme exhibited lower RMSDs compared to its native form. This decrease in RMSD values can be attributed to the high binding affinity and stability of the complexes. When the lowest energy frames of MD simulations for BIA and BTA were superimposed with their best docking conformations, no significant differences were found in the number of hydrophilic and hydrophobic contacts in the active site, as well as all interactions were retained during the MD simulation. In addition, the RMSD values of both compounds from their docking poses showed minimal deviations (Figure 9b), indicating that the molecular docking results are reliable. 
(a)

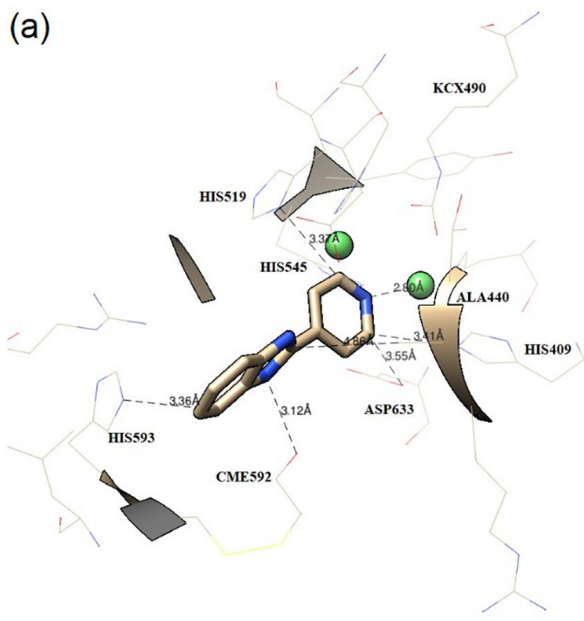

(c)

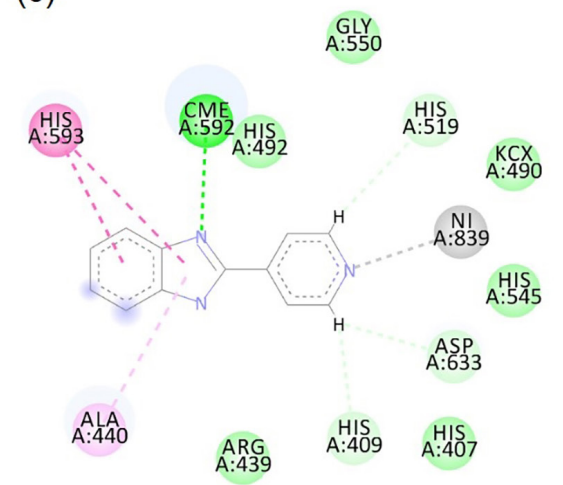

(b)

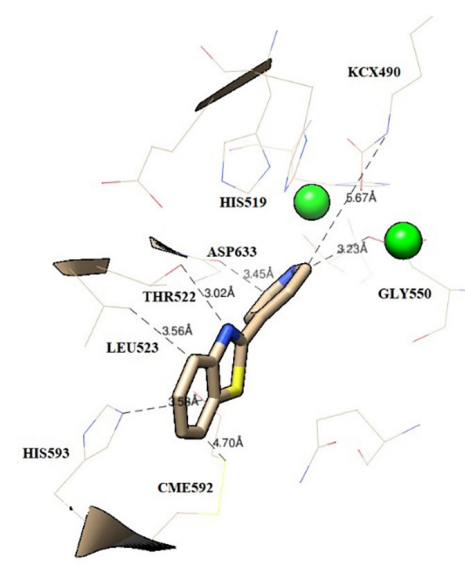

(d)
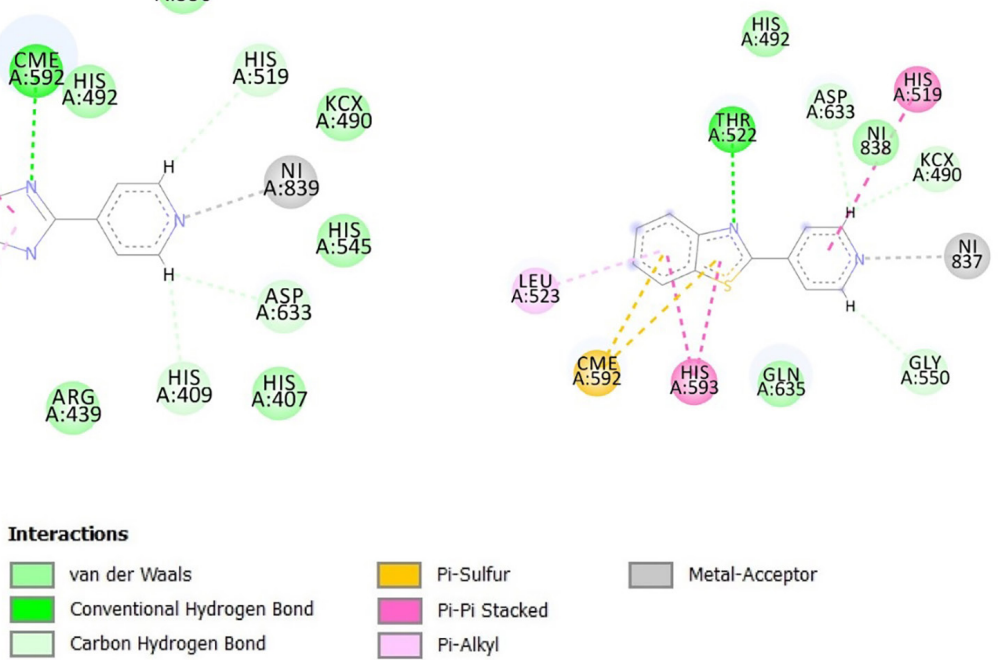

Metal-Acceptor

Figure 8. (a) BIA and (b) BTA interactions with Ni metals and residues from the jack bean urease. The binding conformation of the ligands are shown in stick representation, and green spheres represent the two Ni metals. Coordination with Ni metals, hydrogen bonding, $\pi$ - $\pi$ stacking, $\pi$-alkyl, $\pi$-sulfur, and van der Waals interactions are shown as dotted lines. (c, d) 2D-interaction diagram of BIA and BTA, respectively.

Figure 9c shows a study of the root mean square fluctuation (RMSF) of the native urease and both complexes, which demonstrate the fluctuations of all amino acids, whereas no significant fluctuations were observed at the non-catalytic and binding site in the protein-ligand complexes when compared with the non-complexed target; this was not considered significant for complex formation of BIA and BTA in the active site. However, all interactions of both analogs, in special carbon-hydrogen bond and van der Waals contacts involving histidine residues observed in docking simulations, might explain the polarity of the microenvironment and conformational changes in the neighbors Tyr544 and Trp495 residues, as demonstrated in Figure 10. The fluctuations ranged between 0.08 to 0.1 and 0.07 to $0.18 \mathrm{~nm}$ for Tyr and Trp, respectively. Finally, these results are according to the synchronous fluorescence binding parameters (Table 4).
In vitro anti-H. pylori activities of BTA and BIA

Urease inhibition by enzymatic and fluorometric assays in vitro allowed the elucidation of the interaction mechanisms with the enzyme, enabling further investigation of BTA and BIA's activity against $H$. pylori. The growth of H. pylori is related to the action of urease enzymes since the bacteria is $\mathrm{pH}$-dependent and, due to the activity of these enzymes, it survives the acidic environment of the stomach. Currently, it is estimated that $H$. pylori infect $50 \%$ of the world population and that 15 to $20 \%$ of that amount suffer from more severe diseases, representing a public health problem. Both compounds studied were more effective against most of the tested bacterial strains when compared to omeprazole (OMP; reference drug) and hydroxyurea (HU; reference inhibitor). In addition, BTA is more efficient in five of the six strains evaluated (Table 6); it was the 

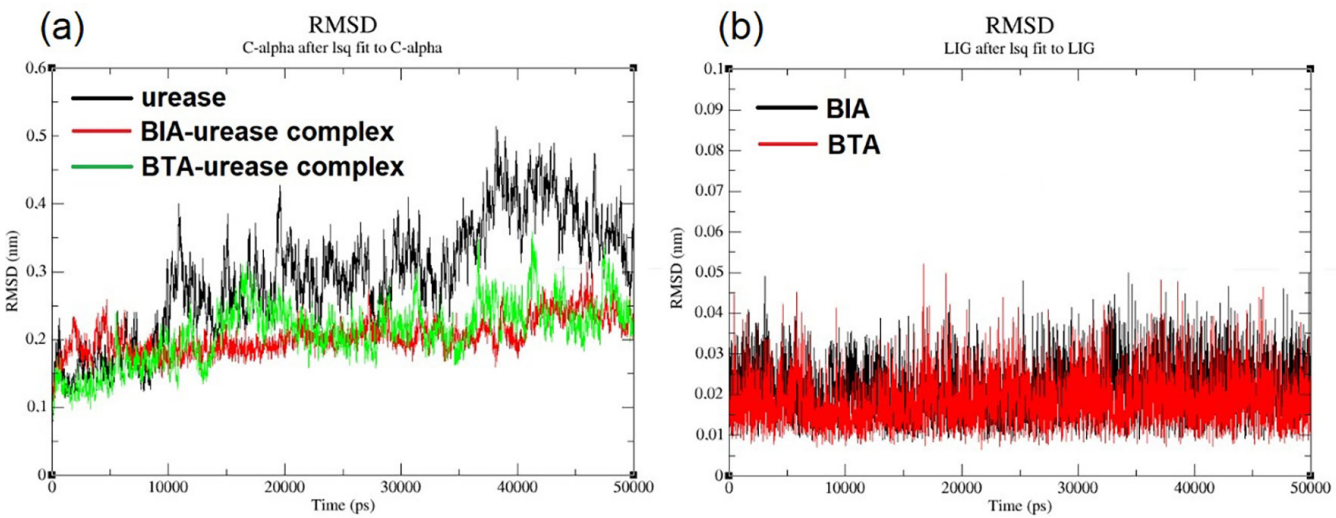

(c)

RMS fluctuation

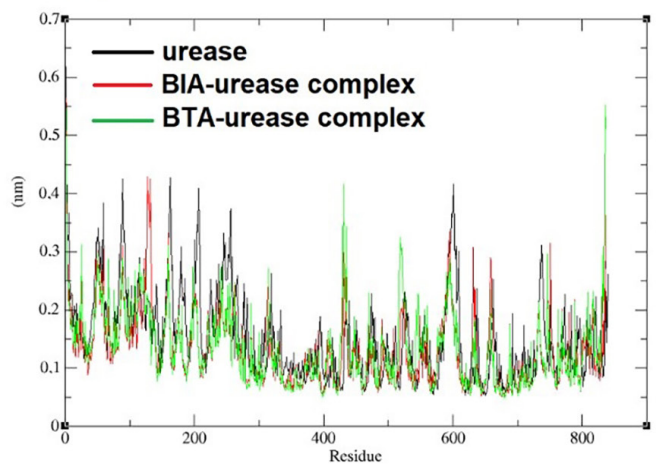

Figure 9. RMSD plots for the C $\alpha$ backbone atoms of the (a) urease and (b) ligands; (c) RMSF plots for the backbone $\mathrm{C}$ atoms of the urease with sequential numbering from the PDB.

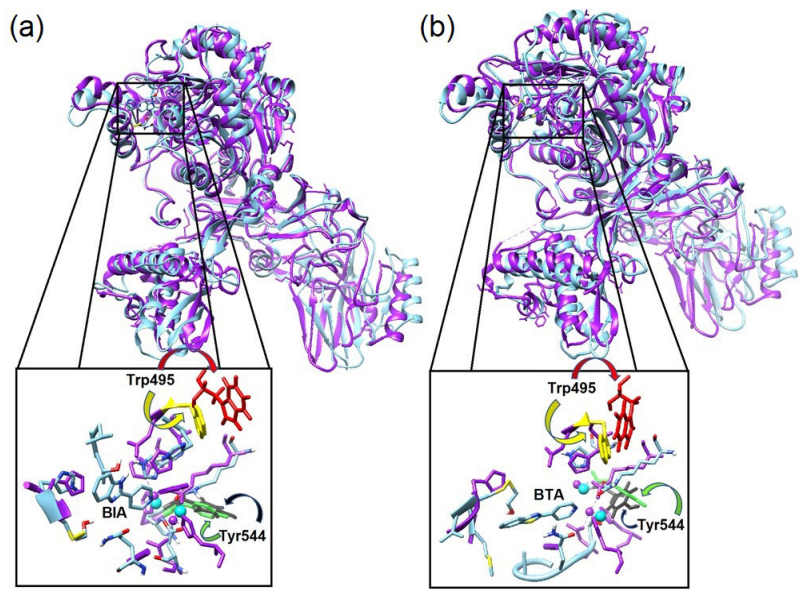

Figure 10. Representative snapshots of the lowest energy frame of MD simulations for (a) BIA and (b) BTA complexes (cyan) superimposed with native urease (purple). Yellow and red show Trp495 residue of native urease and complexes, respectively. Green and dark grey show Tyr544 residue of native urease and complexes, respectively.

compound that had the lowest MIC values, except for strains 110R and R40/499. BIA presented the best activity for all the strains evaluated (Table 6), standing out against strain R40/499 for being 2 times more active than OMP and 168 times more active than HU. The results obtained in models of enzymatic inhibition for ureolytic bacteria can, in some cases, be extrapolated to different bacteria since they present structural similarity in the active site. On the other hand, the compound BTA was more efficient in in vitro studies for both Canavalia ensiformis (jack bean) and $H$. pylori strains. We believe that BTA can be efficient in inhibiting other ureolytic bacteria. For two strains (110R and R40/499), BIA was shown to be more efficient; this can be justified by the mixed inhibition mechanism of the studied inhibitors: although with a structural similarity of the active site, the allosteric site(s) can be distinguished

Table 6. Minimal inhibitory concentration (MIC) of BTA and BIA against $H$. pylori

\begin{tabular}{lcccc}
\hline \multirow{2}{*}{$\begin{array}{l}\text { H. pylori } \\
\text { strain }\end{array}$} & \multicolumn{4}{c}{ MIC $\left(\mathrm{MIC} /\left(\mu \mathrm{mL}^{-1}\right) / \mu \mathrm{M}\right.$} \\
\cline { 2 - 5 } & BTA & BIA & $\begin{array}{c}\text { Omeprazole } \\
(\mathrm{OMP})\end{array}$ & $\begin{array}{c}\text { Hydroxyurea } \\
(\mathrm{HU})\end{array}$ \\
\hline $190^{\mathrm{a} 70}$ & $75(16)$ & $82(16)$ & $92(32)$ & $1683(128)$ \\
E17 $^{\mathrm{a} 85}$ & $75(16)$ & $82(16)$ & $92(32)$ & $1683(128)$ \\
$23^{\text {a 70 }}$ & $150(32)$ & $164(32)$ & $185(64)$ & $3366(256)$ \\
$110 \mathrm{R}^{\mathrm{a} 86}$ & $75(16)$ & $41(8)$ & $46(16)$ & $3366(256)$ \\
R40/499a $^{\mathrm{a} 70}$ & $38(8)$ & $20(4)$ & $46(16)$ & $3366(256)$ \\
R40/442 $^{\mathrm{a} 70}$ & $75(16)$ & $82(16)$ & $92(32)$ & $3366(256)$ \\
NCTC 11637 $^{\mathrm{b}}$ & $75(16)$ & $82(16)$ & $92(32)$ & $3366(256)$ \\
\hline
\end{tabular}

${ }^{\mathrm{a}}$ Clinical isolates; ${ }^{\mathrm{b}}$ reference strain. MIC: minimal inhibitory concentration; BTA: benzothiazole; BIA: benzimidazole. Hydroxyurea (HU) and omeprazole (OMP) were used as a reference for urease inhibitors. 
between different ureases, justifying the different action of BIA against some $H$. pylori strains.

\section{Conclusions}

Benzothiazole BTA $\left(\mathrm{IC}_{50}=0.77 \mathrm{mM}\right)$ and benzimidazole BIA $\left(\mathrm{IC}_{50}=2.14 \mathrm{mM}\right)$ are mixed-inhibitors of jack bean urease with a slight preference to the active site such enzymes. Our biophysical studies supported these conclusions, which also showed the formation of complexes urease-BTA and urease-BIA. The main forces responsible for stabilizing the supramolecular complex between BTA and urease are hydrophobic, while for urease-BIA, van der Waals interactions and hydrogen bonds are the main ones. Finally, both BTA and BIA showed to possess anti-H. pylori activity presenting MIC values in the range of $38-150 \mu \mathrm{M}$ (8-32 $\left.\mathrm{mg} \mathrm{mL}^{-1}\right)$ and $20-164 \mu \mathrm{M}\left(4-32 \mathrm{mg} \mathrm{mL}^{-1}\right)$, respectively.

\section{Experimental}

\section{Chemicals}

All chemicals were obtained from commercial suppliers and used without further purification. Urease (from jack beans, nominal activity 40.1 units $\mathrm{mg}^{-1}$ solid) was from Sigma (St. Louis, USA). Uncorrected melting points were determined in a Gehaka PF 1500 apparatus (São Paulo, Brazil). Reactions under microwave irradiation (MWI) were carried out in a CEM, Microwave-Enhanced Life reactor (Matthews, USA); ${ }^{1} \mathrm{H}$ and ${ }^{13} \mathrm{C}$ NMR spectra were recorded on a Bruker Avance DRX/400 or DPX/200 (Ettlingen, Germany). Chemical shift values $(\delta$ ) were given in parts per million (ppm). IR samples were prepared in $\mathrm{KBr}$ (Vetec, Duque de Caxias, Brazil), while the spectra were recorded in a Spectrometer One PerkinElmer (Waltham, USA). Mass spectra were determined on a Shimadzu LCMS-IT-TOF (Tokyo, Japan).

Single-crystal X-ray diffraction data for BTA and BIA recrystallized from a mixture of equal volumes of ethyl alcohol and water were acquired using a Bruker-AXS Kappa Duo diffractometer (Karlsruhe, Germany) with an APEX II CCD detector. Mo K $\alpha$ radiation from an I $\mu$ S micro source with multilayer optics was used. After diffraction images, harvesting, and treatment, the crystallographic softwares were used: SHELXS- $97^{87}$ for structure solving and refinement and ORTEP- $3{ }^{88}$ for structure analysis and preparation of artworks. For crystal structures of BTA and BIA, see Supplementary Information section. Treatment is shown in Table S1 in the Supplementary Information. A microplate spectrophotometer (Multiskan FC, Thermo Scientific, Woodlands, Singapore) with absorption measurements at $630 \mathrm{~nm}$ was used to study the enzymatic and kinetic activity of urease inhibition. The spectrophotometric measurements were performed in a double beam spectrophotometer Micronal (AJX6100PC, São Paulo, Brazil) equipped with quartz cuvettes of $1.0 \mathrm{~cm}$ optical path. The fluorescence emission spectra were obtained using a spectrofluorimeter (RF-5301PC, Shimadzu, Kyoto, Japan) in $10 \mathrm{~mm}$ optical pathway quartz cells. A $150 \mathrm{~W}$ xenon lamp was used as the excitation source. The UV circular dichroism (CD) spectra were measured using a Jasco CD spectrometer (J-815, Essex, UK) using a quartz cell of $200 \mu \mathrm{L}$ with $0.1 \mathrm{~cm}$ optical path in the range $200-260 \mathrm{~nm}$.

\section{General procedure for the preparation of BTA and BIA}

Benzothiazole BTA was synthesized according to the methodology previously developed by our research group. ${ }^{61}$ Benzimidazole BIA was synthesized according to the methodology developed by de Fátima and co-workers, ${ }^{61}$ with some modifications. Briefly, a mixture of $\mathrm{NaHSO}_{3}$ $(10 \mathrm{mmol})$ and DMA $(2.0 \mathrm{~mL})$ was added to a $10 \mathrm{~mL}$ round bottom flask and then stirred until the homogenization of the reagents. Subsequently, $o$-aminethiophenol $(5.0 \mathrm{mmol})$ was added, besides various aromatic and aliphatic aldehydes $(5.5 \mathrm{mmol})$. The mixture was submitted to MWI for $30 \mathrm{~min}$ at $80{ }^{\circ} \mathrm{C}$. After cooling, the reaction mixtures were placed under water to precipitate the products, then filtered and washed with water. When needed, the solids were recrystallized by using a solution of ethanol and water and dried under vacuum. BTA and BIA were purified by flash chromatography on silica gel (eluent hexane/acetone 9:1).

\section{2-(Pyridin-4yl)benzothiazole (BTA)}

Yield (90\%) as a beige solid; $\mathrm{mp} 129.8-131.2{ }^{\circ} \mathrm{C}$ (lit.: ${ }^{89}$ 130.0-132.0 ${ }^{\circ} \mathrm{C}$ ); IR (KBr) $v / \mathrm{cm}^{-1} 3052,3026,2984,1598$, 1588, 1476, 1406, 1312, 1256, 980, 756, 704; ${ }^{1} \mathrm{H}$ NMR $\left(200 \mathrm{MHz}, \mathrm{DMSO}-d_{6}\right) \delta 8.80(\mathrm{~s}, 2 \mathrm{H}), 8.01-8.20(\mathrm{~m}, 4 \mathrm{H})$, $7.59(\mathrm{~s}, 2 \mathrm{H}) ;{ }^{13} \mathrm{C}$ NMR $\left(50 \mathrm{MHz}\right.$, DMSO- $\left.d_{6}\right) \delta 164.8,153.2$, 150.8, 139.4, 134.7, 126.9, 126.2, 123.4, 122.5, 120.8; LCMS-IT-TOF (liquid chromatography mass spectrometryion trap-time of flight) calculated for $\mathrm{C}_{12} \mathrm{H}_{9} \mathrm{~N}_{2} \mathrm{~S}[\mathrm{M}+\mathrm{H}]^{+}$: 213.0481, found: 213.0422 .

\section{2-(Pyridin-4yl)benzimidazole (BIA)}

Yield (80\%) as a brown solid; $\mathrm{mp} 217.0-217.5{ }^{\circ} \mathrm{C}$ (lit.: $\left.{ }^{62} 217.0{ }^{\circ} \mathrm{C}\right)$; IR $(\mathrm{KBr}) \vee / \mathrm{cm}^{-1} 2887,1608,1585$, 1562, 1435, 1317, 1286, 1238, 1215, 999, 827, 737, 690; ${ }^{1} \mathrm{H}$ NMR $\left(200 \mathrm{MHz}\right.$, DMSO- $\left.d_{6}\right) \delta 8.81(\mathrm{~d}, 2 \mathrm{H}, J 5.1 \mathrm{~Hz})$, $8.20(\mathrm{~d}, 2 \mathrm{H}, J 5.1 \mathrm{~Hz}), 7.67-7.80(\mathrm{~m}, 3 \mathrm{H}), 7.28-7.31(\mathrm{~m}$, $2 \mathrm{H}) ;{ }^{13} \mathrm{C}$ NMR (50 MHz, DMSO- $d_{6}$ ) $\delta 149.5,148.5,139.4$, 
138.6, 123.7, 121.2, 116.1; LCMS-IT-TOF calculated for $\mathrm{C}_{12} \mathrm{H}_{10} \mathrm{~N}_{3}[\mathrm{M}+\mathrm{H}]^{+}:$196.0869, found: 196.0815.

\section{Kinetics and interaction studies with urease}

\section{In vitro urease activity and kinetic assays}

The screening for identifying potential urease inhibitors was performed using the indophenol method essentially as described in the work of de Fátima and co-workers, ${ }^{61}$ in which the reactions consisted of $20 \mathrm{mM}$ phosphate buffer (pH 7.0), 1 mM EDTA (ethylenediamine tetraacetic acid), $10 \mathrm{mM}$ urea, $12.5 \mathrm{mU}$ of Canavalia ensiformis type III urease, in the presence or absence of the compound test at $1.6 \mathrm{mM}$. The ammonium formed was determined $15 \mathrm{~min}$ after the beginning of the reaction. Hydroxyurea (HU) was used as a urease inhibitor reference. Urease inhibition (in percentage) was determined using the formula $100-$ $\left(\mathrm{Abs}_{\text {inhibitor-containing reaction }} / \mathrm{Abs}_{\text {inhibitor-free reaction }}\right) \times 100 .{ }^{90}$ Reactions were also carried out in the presence of increasing concentrations of BTA (0.5-2.0 mM), BIA (1.5-3.0 mM), or $\mathrm{HU}(0.5-2.0 \mathrm{mM})$ to determine the concentration of each compound-test necessary to inhibit urease by $50 \%$ $\left(\mathrm{IC}_{50}\right)$. Four independent experiments were performed in quadruplicate $(n=4)$. The reactions $(n=4)$ for assessing the kinetics parameters were set similarly to the others, except that a fixed concentration of the inhibitor was used in the presence of increasing concentrations of urea (1-32 mM), and the reaction stopped after $10 \mathrm{~min}$ of incubation. The Michaelis-Menten hyperbolas and the Lineweaver-Burk graphs were obtained using the mathematical models used by Modolo and co-workers. ${ }^{61}$

\section{Material and solution preparation for spectroscopic studies}

A stock solution of Canavalia ensiformis (jack bean) type III urease (Sigma, St. Louis, USA) at $10 \mu \mathrm{M}$ was prepared directly in a $20 \mathrm{mM}$ phosphate buffer solution (pH 7.4). Stock solutions of BTA and BIA at $1 \mathrm{mM}$ were prepared in ethanol. Working solutions of competitive inhibitors, BTA and BIA, were prepared at $100 \mu \mathrm{M}$ by direct dissolution or dilution in phosphate buffer solution. All reagents and solvents used were chemically pure.

\section{UV-Vis absorption measurements}

Absorbance was measured for free urease $(3 \mu \mathrm{M})$, ligand $(15 \mu \mathrm{M})$, and ligand-urease mixture to evaluate the complex formation. The UV-Vis absorbance spectra were recorded at $28{ }^{\circ} \mathrm{C}$.

\section{Fluorescence studies}

The urease $(1.0 \mu \mathrm{M})$ fluorescence emission spectra in the absence and presence of increasing amounts of
BTA $(0-40 \mu \mathrm{M})$ and BIA $(0-20 \mu \mathrm{M})$ were recorded using $\lambda_{\mathrm{ex}}=280 \mathrm{~nm}$ and an emission wavelength from 290 to $390 \mathrm{~nm}$ at three temperatures $(293,301,309 \mathrm{~K})$. The excitation and emission slits were 5 and $10 \mathrm{~nm}$, respectively. Synchronous fluorescence spectra of urease in the absence and presence of evaluated compound amounts were obtained by the simultaneous excitation and emission monochromator variation. When necessary, the protein fluorescence signal was corrected to eliminate the inner filter effect. Synchronous fluorescence spectra were recorded, establishing an excitation wavelength as $\lambda_{\text {ex }}=280 \mathrm{~nm}$. The $\Delta \lambda$ value $\left(\Delta \lambda=\lambda_{\text {em }}-\lambda_{\text {ex }}\right)$ between the excitation and emission wavelengths was fixed individually at $\Delta \lambda=15 \mathrm{~nm}$ and $\Delta \lambda=60 \mathrm{~nm}$ and, thus, the spectrum shows only the spectroscopic behavior of tyrosine and tryptophan residues, respectively. ${ }^{91}$ For the competitive assay, substrate (urea) and inhibitors hydroxyurea and omeprazole were used at $25 \mu \mathrm{M}$.

\section{Circular dichroism}

The media of four scans was obtained at $50 \mathrm{~nm} \mathrm{~min}$. The experiments were performed with high purity nitrogen (> 99.9\%) as an inert gas at $20{ }^{\circ} \mathrm{C}$. Urease concentration was $6.0 \mu \mathrm{M}$, while evaluated compounds were $12 \mu \mathrm{M}$ with a maximum methanol content of $3.0 \%(\mathrm{v} / \mathrm{v})$ in the buffer phosphate solution $(\mathrm{pH}=7.4 \pm 0.1)$.

\section{Effect on H. pylori growth}

The MIC values were determined by a modified broth dilution method, as previously described, ${ }^{92}$ on six clinical isolates and the reference strain NCTC 11637. Briefly, a two-fold serial dilution of compounds-test were prepared in a 96-well microtiter plate containing $100 \mu \mathrm{L}$ of MegaCell ${ }^{\mathrm{TM}}$ Roswell Park Memorial Institute (RPMI)-1640 medium (Sigma-Aldrich, St. Louis, MO, USA) supplemented with $3 \%$ fetal calf serum (FCS). An inoculum equivalent to $1 \mathrm{McFarland}$ standard was prepared in Wilkins Chalgren broth and diluted in MegaCell ${ }^{\mathrm{TM}}$ RPMI-1640 medium containing 3\% FCS. Each well was inoculated with $H$. pylori at a final concentration of approximately $5 \times 10^{5}$ colony forming unit (CFU). Plates were incubated at $37{ }^{\circ} \mathrm{C}$ under microaerophilic conditions $\left(10 \% \mathrm{CO}_{2}\right.$ in a gas incubator) and examined $72 \mathrm{~h}$ after incubation.

\section{Theoretical studies}

For the in silico study, the most stable conformation of the jack bean urease (PDB entry: 4H9M) was selected after molecular dynamic (MD) simulations, as previously described by our research group. ${ }^{71}$ Subsequently, HAE, 
BTA, and BIA compounds were drawn and converted into tridimensional structures using the MarvinSketch ${ }^{\circledR}$ software $^{93}$ and the protonation state in neutral $\mathrm{pH}$ (7.4). Also, the compounds were energetically minimized (semi-empiric method Austin Model 1, AM1) using the ArgusLab v. 4.0.1 ${ }^{\circledR}$ software. ${ }^{94}$ All docking simulations were carried out using the Gold 2020 v.1.10.5 ${ }^{\circledR}$ software, ${ }^{84}$ considering the active site from the jack bean urease, with a $6 \AA$ region around the co-crystallized ligand, using the maximum efficiency of the algorithm. For docking protocol validation, RMSD values were obtained by comparing the co-crystallized HAE ligand extracted from the original PDB and HAE binding modes generated by molecular docking using all four scoring functions from the Gold 2020 v.1.10.5 ${ }^{\circledR}$ software, ${ }^{84}$ CHEMPLP, GoldScore, ChemScore, and Astex Statistical Potential (ASP). All molecular alignments of co-crystallized and re-docked ligands were performed using the PyMOL ${ }^{\otimes}$ v. 2.0 software..$^{95}$ Finally, all 2D- and 3D-illustrations were generated using Discovery Studio Visualizer ${ }^{\circledR 96}$ and Chimera $13.1^{\circledR}(3 \mathrm{D})^{97}$ softwares, respectively. For both derivatives, the lowest energy binding poses were chosen as the initial conformations for the MD simulations. In this way, CHARMM36 force field was applied, and the TIP3P solvation method was selected. The ligand topologies were generated using the SwissParam web software. ${ }^{98}$ Thus, a $1.0 \mathrm{~nm}$ triclinic box was created, adding water and ions at the physiological concentration $(0.15 \mathrm{M})$. The system was initially equilibrated in 10,000 steps by the conjugate gradient method, followed by the system's total minimization in 20,000 steps. Then, NVT (constant number of particles, volume, and temperature) and NPT (constant number of particles, pressure, and temperature) balances were performed at a temperature of $300 \mathrm{~K}$, during $10 \mathrm{~ns}$. Finally, the $50 \mathrm{~ns}$ simulation runs were performed with the protein in complex with the BIA and BTA with the system assembled. ${ }^{99}$ Finally, RMSD and RMSF values were calculated based on the analysis of the MD trajectories using GROMACS ${ }^{\circledast}$ v.2018.3 packages $^{100}$ and the Xmgrace tool. ${ }^{101}$

\section{Supplementary Information}

Crystallographic data (excluding structure factors) for the structures in this work were deposited in the Cambridge Crystallographic Data Centre as supplementary publication number CCDC 1538238 and 1538239. Copies of the data can be obtained, free of charge, via https://www.ccdc.cam. ac.uk/structures/.

Supplementary information is available free of charge at http://jbcs.sbq.org.br as a PDF file.

\section{Acknowledgments}

This work was funded by the Fundação de Amparo à Pesquisa do Estado de Minas Gerais (FAPEMIG, Brazil; grants APQ-02187-17 and APQ-03069-18), Conselho Nacional de Desenvolvimento Científico e Tecnológico (CNPq, Brazil; grants 306537/2016-8, 420548/2018-1 and 307475/2019-0), this study was financed in part by the Coordenação de Aperfeiçoamento de Pessoal de Nível Superior (CAPES, Brazil; finance code 001), Fundação de Amparo à Pesquisa do Estado de Alagoas (FAPEAL, Brazil). This work used resources of the Centro Nacional de Processamento de Alto Desempenho em São Paulo (CENAPAD-SP). Authors thank to Mr Michel Breno José da Silva for help in preparing BTA and BIA. A. D. F., J. C. C. S. and L. V. M. are recipient of research fellowship from CNPq, Brazil.

\section{Author Contributions}

Camila P. Pereira was responsible for the methodology, formal analysis, validation, visualization; Ana C. F. de Lyra for the methodology, formal analysis, validation, visualization; Breno G. F. Oliveira for the methodology, formal analysis, writing original draft and review editing, visualization; Igor J. S. Nascimento for the methodology, validation, software, visualization; Edeildo F. da Silva Júnior for the methodology, resources, software, writing original draft, visualization; Thiago M. de Aquino for the conceptualization, resources, software, methodology, validation, writing original draft, visualization; Francesca Sisto for the methodology, resources, validation, formal analysis, writing original draft and review editing, visualization; Isis M. Figueiredo for the resources,writing original draft, visualization; Felipe T. Martins for the methodology, resources, software, validation, writing original draft, visualization; Luzia V. Modolo for the methodology, resources, formal analysis, writing original draft, visualization; Josué C. C. Santos for the conceptualization, funding acquisition, resources, methodology, writing original draft and review editing, visualization and supervision; Ângelo de Fátima for the conceptualization, funding acquisition, resources, methodology, writing original draft and review editing, visualization and supervision.

\section{References}

1. Mobley, H. L.; Hausinger, R. P.; Microbiol. Rev. 1989, 53, 85.

2. Krajewska, B.; J. Mol. Catal. B: Enzym. 2009, 59, 9.

3. Modolo, L. V.; de Souza, A. X.; Horta, L. P.; Araujo, D. P.; de Fátima, Â.; J. Adv. Res. 2015, 6, 35.

4. Kappaun, K.; Piovesan, A. R.; Carlini, C. R.; Ligabue-Braun, R.; J. Adv. Res. 2018, 13, 3.

5. Follmer, C.; J. Clin. Pathol. 2010, 63, 424. 
6. Maroney, M. J.; Ciurli, S.; Chem. Rev. 2014, 114, 4206.

7. Boer, J. L.; Mulrooney, S. B.; Hausinger, R. P.; Arch. Biochem. Biophys. 2014, 544, 142.

8. Raz, R.; Colodner, R.; Kunin, C. M.; Clin. Infect. Dis. 2005, 40, 896.

9. Nielubowicz, G. R.; Mobley, H. L. T.; Nat. Rev. Urol. 2010, 7, 430.

10. Flores-Mireles, A. L.; Walker, J. N.; Caparon, M.; Hultgren, S. J.; Nat. Rev. Microbiol. 2015, 13, 269.

11. Amtul, Z.; Atta-ur-Rahman, B. S. P.; Siddiqui, R.; Choudhary, M.; Curr. Med. Chem. 2002, 9, 1323.

12. Rego, Y. F.; Queiroz, M. P.; Brito, T. O.; Carvalho, P. G.; de Queiroz, V. T.; de Fátima, Â.; Macedo Jr., F.; J. Adv. Res. 2018, 13,69 .

13. Kafarski, P.; Talma, M.; J. Adv. Res. 2018, 13, 101.

14. de Fátima, Â.; Pereira, C. P.; Olímpio, C. R. S. D. G.; Oliveira, B. G. F.; Franco, L. L.; da Silva, P. H. C.; J. Adv. Res. 2018, 13, 113.

15. Kazimierczuk, Z.; Andrzejewska, M.; Kaustova, J.; Klimešova, V.; Eur. J. Med. Chem. 2005, 40, 203.

16. Sadek, B.; Al-Tabakha, M. M.; Fahelelbom, K. M. S.; Molecules 2011, 16, 9386.

17. Reddy, M. S.; Anisetti, R. N.; Prasad, K. D.; Sannigrahi, S.; Reddy, P. A.; Pharm. Chem. J. 2011, 44, 642.

18. Ravishankara, D. K.; Chandrashekara, P. G.; Eur. J. Chem. 2012, 3,359 .

19. Zhou, B.; Li, B.; Yi, W.; Bu, X.; Ma, L.; Bioorg. Med. Chem. Lett. 2013, 23, 3759.

20. Chen, P.-J.; Yang, A.; Gu, Y.-F.; Zhang, X.-S.; Shao, K.-P.; Xue, D.-Q.; He, P.; Jiang, T.-F.; Zhang, Q.-R.; Liu, H.-M.; Bioorg. Med. Chem. Lett. 2014, 24, 2741.

21. Huang, W.; Zhao, P.-L.; Liu, C.-L.; Chen, Q.; Liu, Z.-M.; Yang, G.-F.; J. Agric. Food Chem. 2007, 55, 3004.

22. Ban, M.; Taguchi, H.; Katsushima, T.; Takahashi, M.; Shinoda, K.; Watanabe, A.; Tominaga, T.; Bioorg. Med. Chem. 1998, 6, 1069.

23. Garuti, L.; Roberti, M.; Gentilomi, G.; Il Farmaco 2001, 56, 815.

24. Biron, K. K.; Harvey, R. J.; Chamberlain, S. C.; Good, S. S.; Smith, A. A.; Davis, M. G.; Talarico, C. L.; Miller, W. H.; Ferris, R.; Dornsife, R. E.; Stanat, S. C.; Drach, J. C.; Townsend, L. B.; Koszalka, G. W.; Antimicrob. Agents Chemother. 2002, 46 , 2365.

25. Ishida, T.; Suzuki, T.; Hirashima, S.; Mizutani, K.; Yoshida, A.; Ando, I.; Ikeda, S.; Adachi, T.; Hashimoto, H.; Bioorg. Med. Chem. Lett. 2006, 16, 1859.

26. Budow, S.; Kozlowska, M.; Gorska, A.; Kazimierczuk, Z.; Eickmeier, H.; La Colla, P.; Gosselin, G.; Seela, F.; Arkivoc 2009, 225.

27. Hall, I. H.; Peaty, N. J.; Henry, J. R.; Easmon, J.; Heinisch, G.; Pürstinger, G.; Arch. Pharm. (Weinheim) 1999, 332, 115.
28. Wells, G.; Bradshaw, T. D.; Diana, P.; Seaton, A.; Shi, D.-F.; Westwell, A. D.; Stevens, M. F. G.; Bioorg. Med. Chem. Lett. 2000, 10, 513.

29. Hose, C. D.; Hollingshead, M.; Sausville, E. A.; Monks, A.; Mol. Cancer Ther. 2003, 2, 1265.

30. Leong, C.-O.; Gaskell, M.; Martin, E. A.; Heydon, R. T.; Farmer, P. B.; Bibby, M. C.; Cooper, P. A.; Double, J. A.; Bradshaw, T. D.; Stevens, M. F. G.; Br. J. Cancer 2003, 88, 470.

31. Fichtner, I.; Monks, A.; Hose, C.; Stevens, M. F. G.; Bradshaw, T. D.; Breast Cancer Res. Treat. 2004, 87, 97.

32. Bradshaw, T.; Westwell, A.; Curr. Med. Chem. 2004, 11, 1009.

33. Brantley, E.; Patel, V.; Stinson, S. F.; Trapani, V.; Hose, C. D.; Ciolino, H. P.; Yeh, G. C.; Gutkind, J. S.; Sausville, E. A.; Loaiza-Pérez, A. I.; Anticancer. Drugs 2005, 16, 137.

34. Mortimer, C. G.; Wells, G.; Crochard, J.-P.; Stone, E. L.; Bradshaw, T. D.; Stevens, M. F. G.; Westwell, A. D.; J. Med. Chem. 2006, 49, 179.

35. Andrzejewska, M.; Yepez-Mulia, L.; Tapia, A.; Cedillo-Rivera, R.; Laudy, A. E.; Starościak, B. J.; Kazimierczuk, Z.; Eur. J. Pharm. Sci. 2004, 21, 323.

36. Pérez-Villanueva, J.; Santos, R.; Hernández-Campos, A.; Giulianotti, M. A.; Castillo, R.; Medina-Franco, J. L.; Med. Chem. Commun. 2011, 2, 44.

37. Pérez-Villanueva, J.; Hernández-Campos, A.; Yépez-Mulia, L.; Méndez-Cuesta, C.; Méndez-Lucio, O.; Hernández-Luis, F.; Castillo, R.; Bioorg. Med. Chem. Lett. 2013, 23, 4221.

38. Farahat, A. A.; Bennett-Vaughn, C.; Mineva, E. M.; Kumar, A.; Wenzler, T.; Brun, R.; Liu, Y.; Wilson, W. D.; Boykin, D. W.; Bioorg. Med. Chem. Lett. 2016, 26, 5907.

39. Taha, M.; Sain, A. A.; Ali, M.; Anouar, E. H.; Rahim, F.; Ismail, N. H.; Adenan, M. I.; Imran, S.; Al-Harrasi, A.; Nawaz, F.; Iqbal, N.; Khan, K. M.; Bioorg. Chem. 2020, 99, 103819.

40. Bryson, H. M.; Fulton, B.; Benfield, P.; Drugs 1996, 52, 549.

41. Cifra, A.; Mazzone, G. L.; Nistri, A.; Neuroscience 2013, 19, 137.

42. Mancini, A.; Chelini, A.; Di Capua, A.; Castelli, L.; Brogi, S.; Paolino, M.; Giuliani, G.; Cappelli, A.; Frosini, M.; Ricci, L.; Leonelli, E.; Giorgi, G.; Giordani, A.; Magistretti, J.; Anzini, M.; Eur. J. Med. Chem. 2017, 126, 614.

43. Shamim, S.; Khan, K. M.; Ullah, N.; Chigurupati, S.; Wadood, A.; Ur Rehman, A.; Ali, M.; Salar, U.; Alhowail, A.; Taha, M.; Perveen, S.; Bioorg. Chem. 2020, 101, 103979.

44. Akande, A. A.; Salar, U.; Khan, K. M.; Syed, S.; Aboaba, S. A.; Chigurupati, S.; Wadood, A.; Riaz, M.; Taha, M.; Bhatia, S.; Kanwal; Shamim, S.; Perveen, S.; ACS Omega 2021, 6, 22726.

45. Ullah, H.; Ullah, H.; Taha, M.; Khan, F.; Rahim, F.; Uddin, I.; Sarfraz, M.; Shah, S. A. A.; Aziz, A.; Mubeen, S.; Russ. J. Org. Chem. 2021, 57, 968.

46. Taha, M.; Uddin, N.; Ali, M.; Anouar, E. H.; Rahim, F.; Khan, G.; Farooq, R. K.; Gollapalli, M.; Iqbal, N.; Farooq, M.; Khan, K. M.; Int. J. Biol. Macromol. 2020, 161, 355. 
47. Gull, Y.; Rasool, N.; Noreen, M.; Nasim, F.-H.; Yaqoob, A.; Kousar, S.; Rashid, U.; Bukhari, I.; Zubair, M.; Islam, M.; Molecules 2013, 18, 8845 .

48. Koszalka, G. W.; Johnson, N. W.; Good, S. S.; Boyd, L.; Chamberlain, S. C.; Townsend, L. B.; Drach, J. C.; Biron, K. K.; Antimicrob. Agents Chemother. 2002, 46, 2373.

49. Krosky, P. M.; Baek, M.-C.; Coen, D. M.; J. Virol. 2003, 77, 905.

50. De Clercq, E.; Nat. Rev. Microbiol. 2004, 2, 704.

51. Bugnoli, M.; Bayeli, P. F.; Rappuoli, R.; Pennatini, C.; Figura, N.; Crabtree, J. E.; Eur. J. Gastroenterol. Hepatol. 1993, 5, 683.

52. Mirshahi, F.; Fowler, G.; Patel, A.; Shaw, G.; J. Clin. Pathol. 1998, 51, 220.

53. Covacci, A.; Telford, J. L.; Del Giudice, G.; Parsonnet, J.; Rappuoli, R.; Science 1999, 284, 1328.

54. Kusters, J. G.; van Vliet, A. H. M.; Kuipers, E. J.; Clin. Microbiol. Rev. 2006, 19, 449.

55. Eaton, K. A.; Brooks, C. L.; Morgan, D. R.; Krakowka, S.; Infect. Immun. 1991, 59, 2470.

56. Scott, D. R.; Marcus, E. A.; Weeks, D. L.; Sachs, G.; Gastroenterology 2002, 123, 187.

57. Bauerfeind, P.; Garner, R.; Dunn, B. E.; Mobley, H. L.; Gut 1997, 40, 25.

58. van Vliet, A. H. M.; Kuipers, E. J.; Waidner, B.; Davies, B. J.; de Vries, N.; Penn, C. W.; Vandenbroucke-Grauls, C. M. J. E.; Kist, M.; Bereswill, S.; Kusters, J. G.; Infect. Immun. 2001, 69, 4891.

59. Contreras, M.; Thiberge, J.-M.; Mandrand-Berthelot, M.-A.; Labigne, A.; Mol. Microbiol. 2003, 49, 947.

60. Rutherford, J. C.; PLoS Pathog. 2014, 10, e1004062.

61. Araujo, D. P.; Morais, V. S. S.; de Fátima, Â.; Modolo, L. V.; $R S C A d v .2015,5,28814$.

62. Moorthy, J. N.; Neogi, I.; Tetrahedron Lett. 2011, 52, 3868.

63. Geiger, D. K.; Bond, C. J.; Acta Crystallogr., Sect. E: Struct. Rep. Online 2013, 69, o869.

64. Ghisaidoobe, A.; Chung, S.; Int. J. Mol. Sci. 2014, 15, 22518.

65. Dantas, M. D. A.; Tenório, H. A.; Lopes, T. I. B.; Pereira, H. J. V.; Marsaioli, A. J.; Figueiredo, I. M.; Santos, J. C. C.; Int. J. Biol. Macromol. 2017, 102, 505.

66. Albani, J. R.; Principles and Applications of Fluorescence Spectroscopy; Blackwell Publishing Ltd: Oxford, UK, 2007.

67. da Silva, C. M.; Silva, M. M.; Reis, F. S.; Ruiz, A. L. T. G.; de Carvalho, J. E.; Santos, J. C. C.; Figueiredo, I. M.; Alves, R. B.; Modolo, L. V.; de Fátima, Â.; J. Photochem. Photobiol., B 2017, 172, 129.

68. de Barros, W. A.; Silva, M. M.; Dantas, M. D. A.; Santos, J. C. C.; Figueiredo, I. M.; Chaves, O. A.; Sant'Anna, C. M. R.; de Fátima, Â.; New J. Chem. 2021, 45, 13158.

69. Santos, J. C. N.; da Silva, I. M.; Braga, T. C.; de Fátima, Â.; Figueiredo, I. M.; Santos, J. C. C.; Int. J. Biol. Macromol. 2018, $113,1032$.
70. Lage, T. C. A.; Maciel, T. M. S.; Mota, Y. C. C.; Sisto, F.; Sabino, J. R.; Santos, J. C. C.; Figueiredo, I. M.; Masia, C.; de Fátima, Â.; Fernandes, S. A.; Modolo, L. V.; New J. Chem. 2018, 42, 5356.

71. Braga, T. C.; Silva, T. F.; Maciel, T. M. S.; da Silva, E. C. D.; da Silva-Júnior, E. F.; Modolo, L. V.; Figueiredo, I. M.; Santos, J. C. C.; de Aquino, T. M.; de Fátima, Â.; New J. Chem. 2019, $43,15187$.

72. Wang, Y.-Q.; Zhang, G.-C.; Zhang, H.-M.; J. Solution Chem. 2011, $40,458$.

73. Zhang, H.-M.; Zhang, G.-C.; Wang, Y.-Q.; Biol. Trace Elem. Res. 2011, 141, 53.

74. Yan-Qing, W.; Hong-Mei, Z.; Spectrochim. Acta, Part A 2012, 96, 352.

75. Ross, P. D.; Subramanian, S.; Biochemistry 1981, 20, 3096.

76. Santana, C. C.; Silva-Júnior, E. F.; Santos, J. C. N.; Rodrigues, É. E. S.; da Silva, I. M.; Araújo-Júnior, J. X.; do Nascimento, T. G.; Barbosa, L. A. O.; Dornelas, C. B.; Figueiredo, I. M.; Santos, J. C. C.; Grillo, L. A. M.; Bioorg. Chem. 2019, 87, 169.

77. de Lyra, A. C. F.; Silva, A. L. S.; dos Santos, E. C. L.; López, A. M. Q.; da Silva, J. C. S.; Figueiredo, I. M.; Santos, J. C. C.; Spectrochim. Acta, Part A 2020, 228, 117747.

78. Balasubramanian, A.; Ponnuraj, K.; J. Mol. Biol. 2010, 400, 274.

79. Takishima, K.; Suga, T.; Mamiya, G.; Eur. J. Biochem. 1988, 175, 151.

80. Silva, M. M.; Dantas, M. D. A.; da Silva Filho, R. C.; Sales, M. V. S.; Xavier, J. A.; Leite, A. C. R.; Goulart, M. O. F.; Grillo, L. A. M.; de Barros, W. A.; de Fátima, Â.; Figueiredo, I. M.; Santos, J. C. C.; Int. J. Biol. Macromol. 2020, 154, 661.

81. Sydor, A. M.; Liu, J.; Zamble, D. B.; J. Bacteriol. 2011, 193, 1359.

82. Satzer, P.; Svec, F.; Sekot, G.; Jungbauer, A.; Eng. Life Sci. 2016, 16, 238.

83. Ponnuvel, S.; Subramanian, B.; Ponnuraj, K.; Protein J. 2015, 34, 329.

84. Jones, G.; Willett, P.; Glen, R. C.; Leach, A. R.; Taylor, R.; J. Mol. Biol. 1997, 267, 727.

85. Sisto, F.; Scaltrito, M. M.; Masia, C.; Bonomi, A.; Coccè, V.; Marano, G.; Haynes, R. K.; Miani, A.; Farronato, G.; Taramelli, D.; Int. J. Antimicrob. Agents 2016, 48, 101.

86. Brenciaglia, M. I.; Fornara, A. M.; Scaltrito, M. M.; Dubini, F.; Int. J. Antimicrob. Agents 1996, 6, 223.

87. Sheldrick, G. M.; Acta Crystallogr., Sect. A: Found. Crystallogr. 2008, 64, 112.

88. Farrugia, L. J.; J. Appl. Crystallogr. 2012, 45, 849.

89. Gorepatil, P.; Mane, Y.; Ingle, V.; Synlett 2013, 24, 2241.

90. Khan, M.-H.; Hameed, S.; Yasin, K. A.; Akhtar, T.; Khan, K. M.; Monatsh. Chem. 2010, 141, 479.

91. Chen, J.; Zhou, X.; Zhang, Y.; Gao, H.; Sci. Total Environ. 2012, 432, 269. 
92. Sisto, F.; Scaltrito, M. M.; Russello, G.; Bonomi, A.; Dubini, F.; Curr. Microbiol. 2009, 58, 559.

93. MarvinSketch, version 20.3; ChemAxon Ltd., United States, 2020.

94. Thompson, M.; ArgusLab, version 4.0.1; Planaria Software LLC, United States, 2004.

95. The PyMOL Molecular Graphics System, version 2.0; Schrödinger, LLC, USA, 2019.

96. Dassault Systèmes BIOVIA; Discovery Studio Visualizer, version 4.5; Dassault Systèmes, San Diego, USA, 2016.

97. Pettersen, E. F.; Goddard, T. D.; Huang, C. C.; Couch, G. S.; Greenblatt, D. M.; Meng, E. C.; J. Comput. Chem. 2004, 25, 1605.
98. SwissParam; http://www.swissparam.ch/, accessed in January 2022.

99. Passos, G. F. S.; Gomes, M. G. M.; de Aquino, T. M.; de AraújoJúnior, J. X.; de Souza, S. J. M.; Cavalcante, J. P. M.; dos Santos, E. C.; Bassi, Ê. J.; da Silva-Júnior, E. F.; Pharmaceuticals 2020, 13,141 .

100. Hess, B.; Kutzner, C.; van der Spoel, D.; Lindahl, E.; J. Chem. Theory Comput. 2008, 4, 435.

101. Turner P. J.; XMGRACE, version 5.1.19; Center for Coastal and Land-Margin Research, Oregon Graduate Institute of Science and Technology, Beaverton, OR, USA, 2005.

Submitted: September 13, 2021

Published online: January 28, 2022 